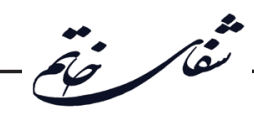

\title{
Neuroendocrine Role of Kisspeptin-Neurokinin B-Dynorphin Pathway in Male Fertility and its Correlation with Melatonin
} Najmeh Davoodian ${ }^{1}$, Reza Khetvan-Hafshejani' ${ }^{2}$ Ali Kadivar ${ }^{2}$, Sayed Mostafa Modarres Mousavi $^{3,4}$, Ehsan Aali ${ }^{5}$, Amir $^{7}$
Gheami $^{6}$, Behnam Bakhtiari Moghaddam ${ }^{7}$, Sadegh Shirian $^{7,8^{*}}$

\author{
${ }^{1}$ Research Institute of Animal Embryo Technology, Shahrekord University, Shahrekord, Iran \\ ${ }^{2}$ Department of Clinical Sciences, Faculty of Veterinary Medicine, Shahrekord University, Shahrekord, Iran \\ ${ }^{3}$ Department of Nanobiotechnology, Faculty of Biological Sciences, Tarbiat Modares University, Tehran, Iran \\ ${ }^{4}$ Shefa Neuroscience Research Center, Khatam Alanbia Hospital, Tehran, Iran \\ ${ }^{5}$ Department of Pharmacology, Qazvin University of Medical Sciences, Qazvin, Iran \\ ${ }^{6}$ Department of Virology, Pasteur Institute of Iran, Tehran, Iran \\ ${ }^{7}$ Department of Pathology, Faculty of Veterinary Medicine, Shahrekord University, Shahrekord, Iran \\ ${ }^{8}$ Shiraz Molecular Pathology Research Center, Dr Daneshbod Lab, Shiraz, Iran
}

Article Info:

\section{A BSTRACT}

Introduction: A subset of neurons has been recently identified in the arcuate nucleus of the hypothalamus that co-localize three neuropeptides; kisspeptin, neurokinin B, and dynorphin (KNDy). These neuropeptides have been shown to play a critical role in the central control of reproduction and the modulation of gonadotrophin releasing hormone $(\mathrm{GnRH})$ secretion by endocrine, metabolic and environmental inputs. KNDy also acts as a novel potential therapeutic target in the treatment of fertility disorders. Infertility following chemotherapy is particularly common in male survivors of childhood cancer and for testicular cancer survivors. Early human studies have suggested that peripheral exogenous Kisspeptin administration stimulates GnRH secretion in healthy adults and in patients with some forms of infertility. In this review, we describe our current understanding of the neural systems mediating the actions of KNDy neurons on GnRH pulse generation and male fertility. In addition, the effect of melatonin treatment on the GnRH neuronal system and its effect on kisspeptin and gonadotropin-inhibitory neurons are discussed. Conclusion: Further researches about functional and molecular mechanisms of KNDy pathway, endogenous opioid peptide, and antioxidant agents, such as melatonin, may develop novel approaches to treat chemotherapy induced-infertility in males.

\section{Key words:}

1. Neuroendocrinology

2. Fertility

3. Melatonin

4. Male

5. Gonadotropins

*Corresponding Author: Sadegh Shirian

E-mail: shirian85@gmail.com 
نقش مسير نورواندكرين كيسيتين -نوروكينين B- دى نورفين در بارورى مردان و ارتباط آن با ملاتونين

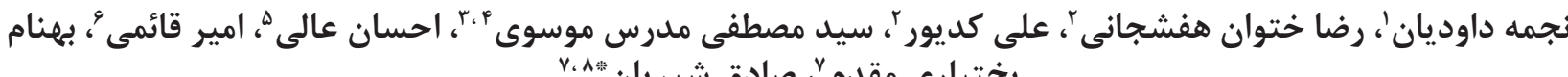

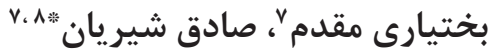

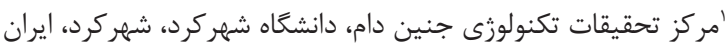

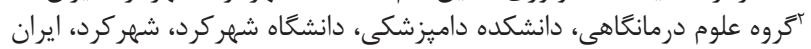

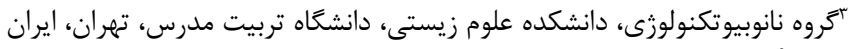

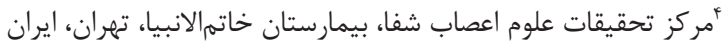

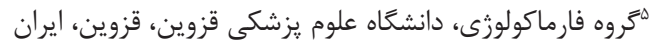

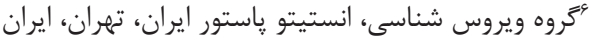

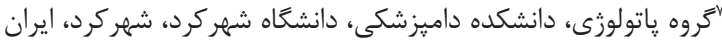

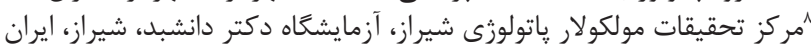

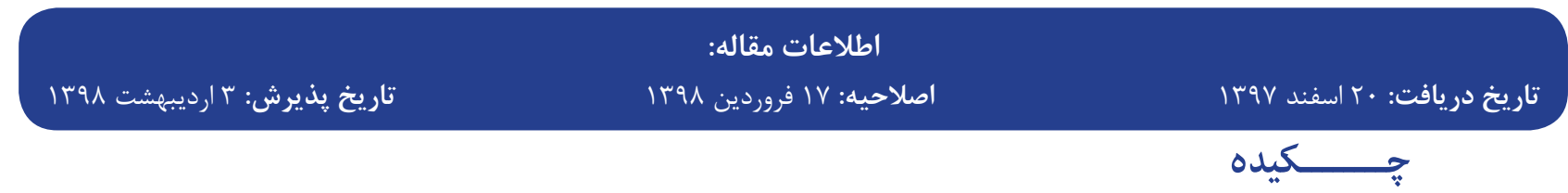

مقدمه: اخيراً زيرمجموعهاى از نورونها در هستههاى arcuate هييوتالاموس شناسايى شدهاند كه سه سه

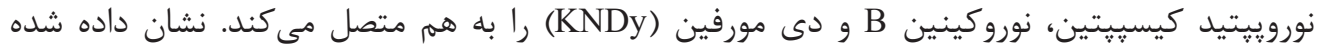

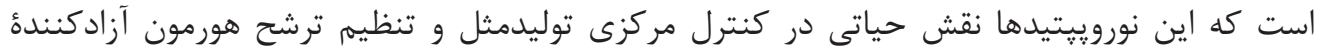

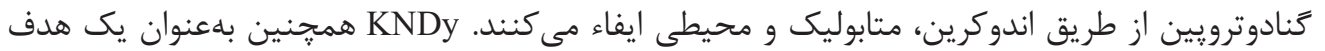

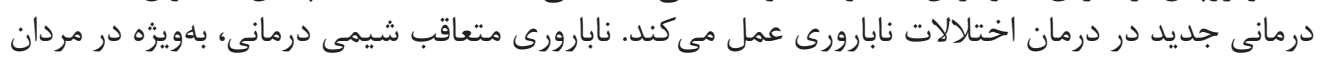

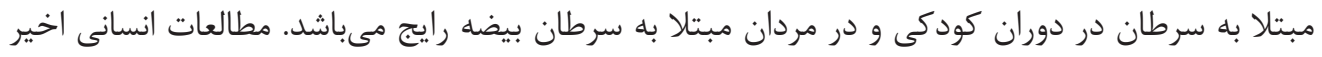

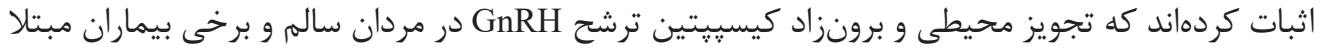

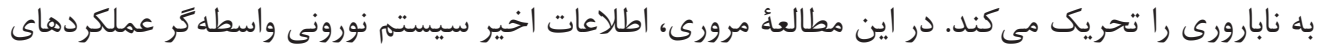

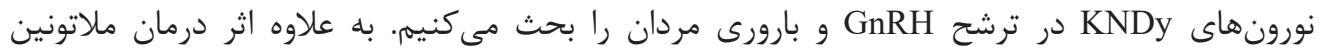

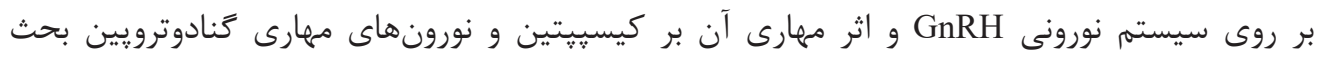

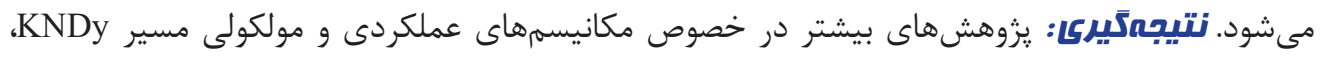

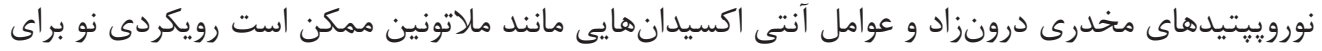
درمان نابارورى القاء شده توسط شيمى درمانى در مردان راني اتوسعه دهدي.

(ب:

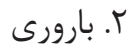

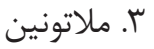
ن:

ه. كَنادوترويينها 


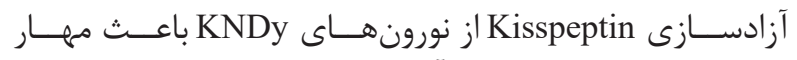

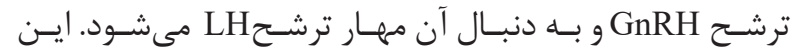

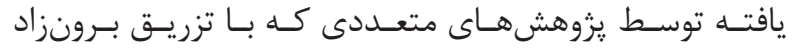

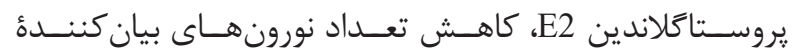

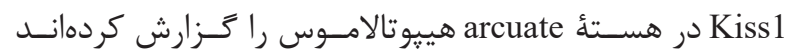

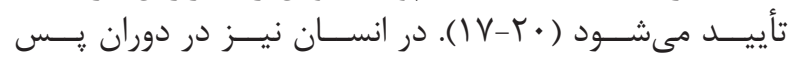

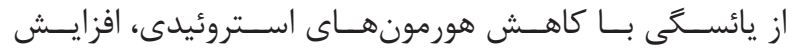

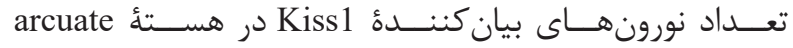

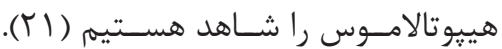

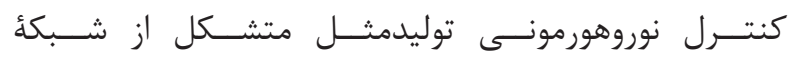

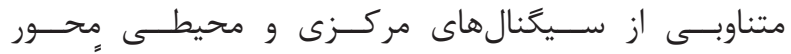

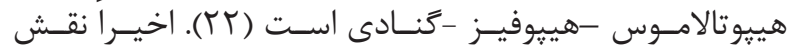

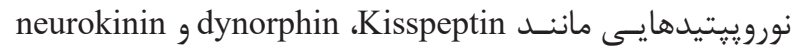

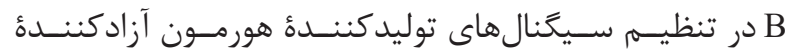

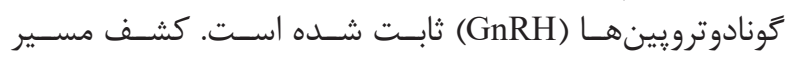

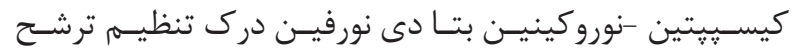

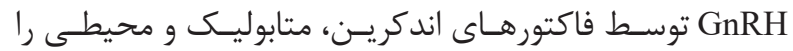

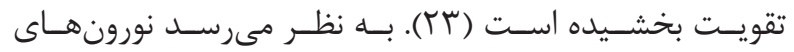

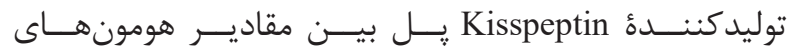

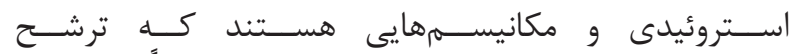

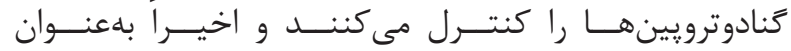

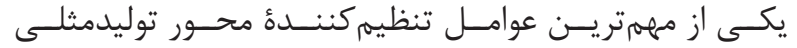

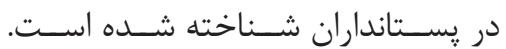

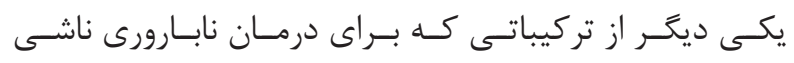

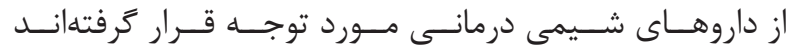

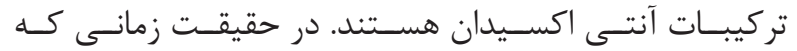

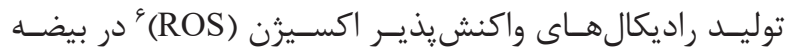

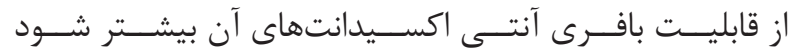

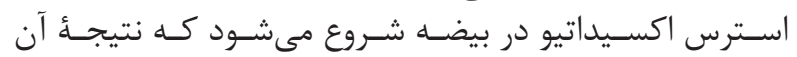

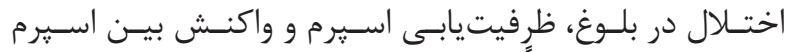

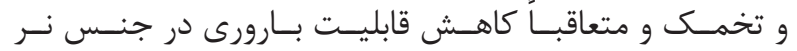

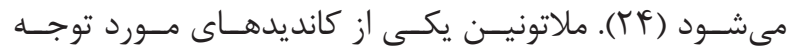

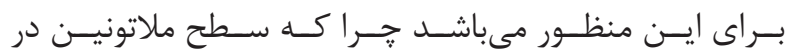

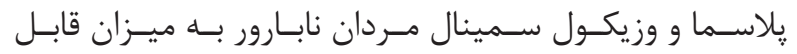

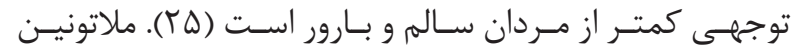

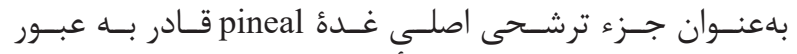

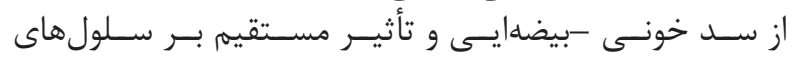

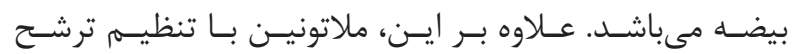

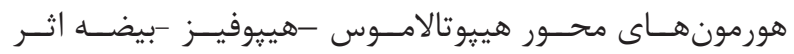

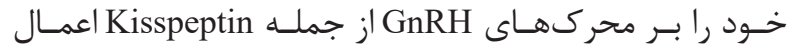

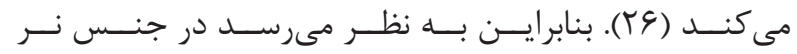

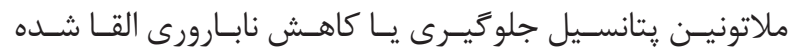

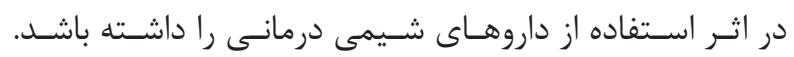

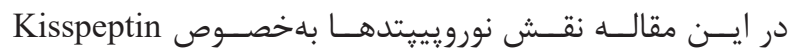

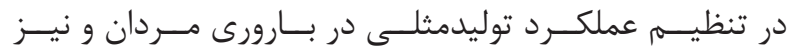

\section{${ }^{1}$ Azoospermia}

${ }^{2}$ Dynorphin

${ }^{3}$ Kisspeptin /neurokinin B/dynorphin

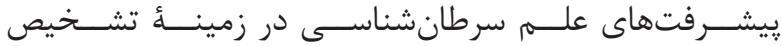

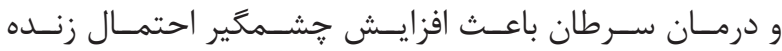

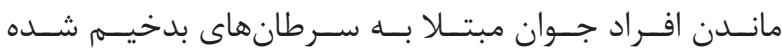

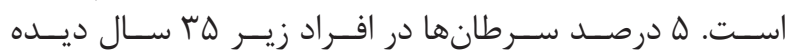

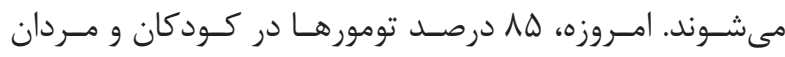

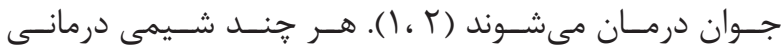

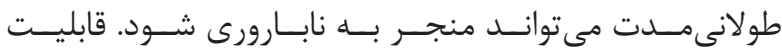

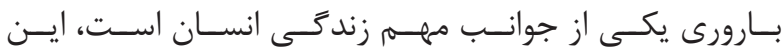

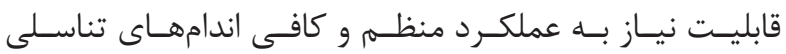

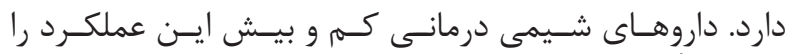

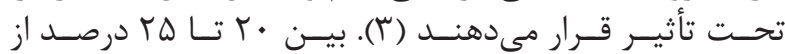

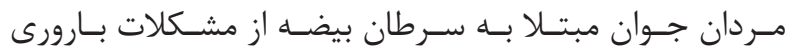

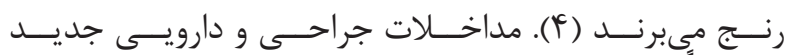

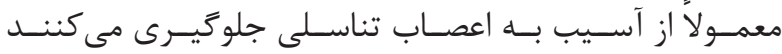

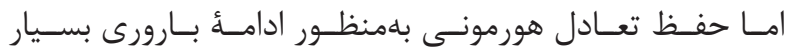

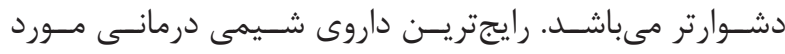

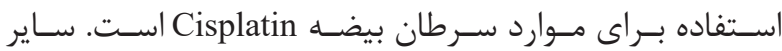

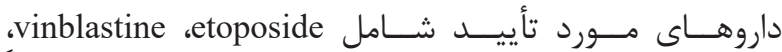
هusulfan ifosfamide bleomycin

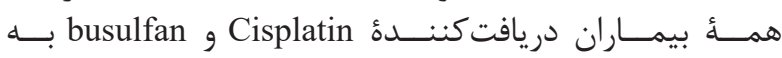

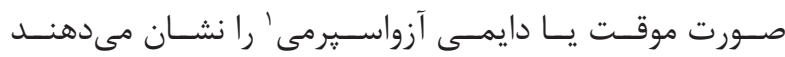

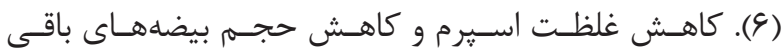

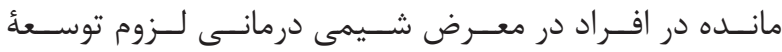

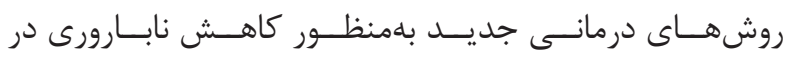

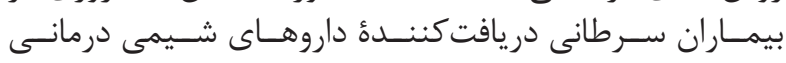

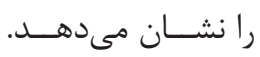

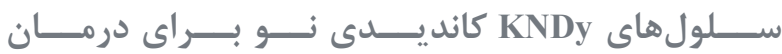

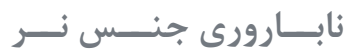

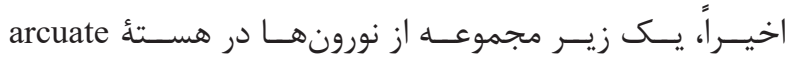

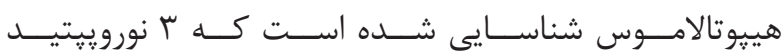

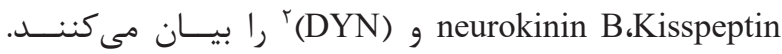

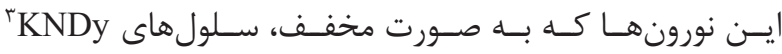

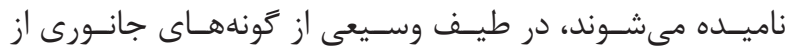

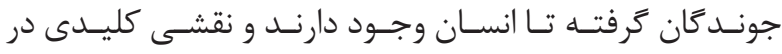

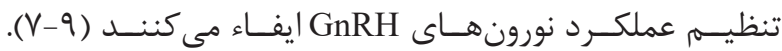

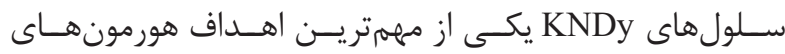

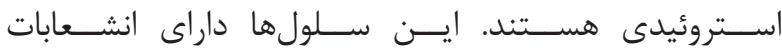

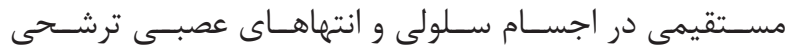

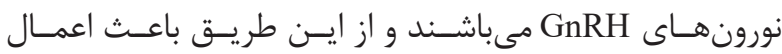

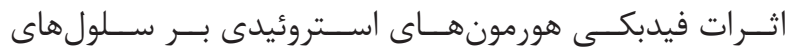

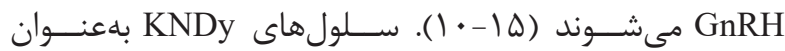

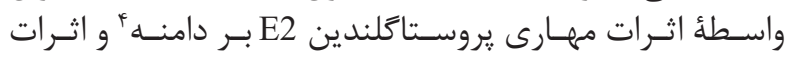

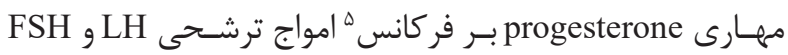

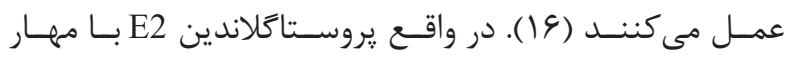

\footnotetext{
${ }^{4}$ Amplitude

${ }^{5}$ Frequency

${ }^{6}$ Reactive oxygen species
} 


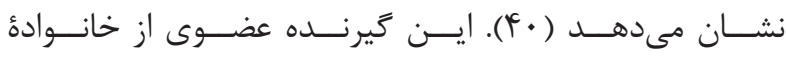

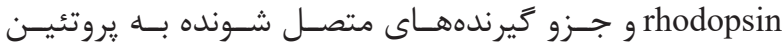

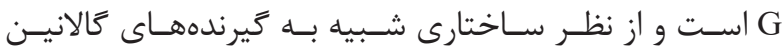

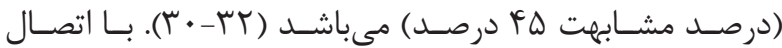

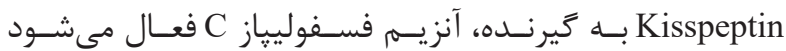

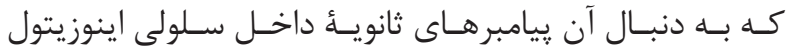

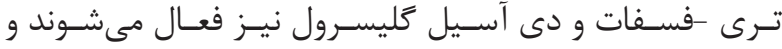

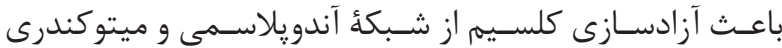

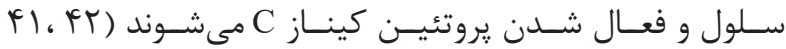

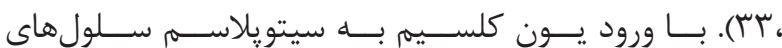

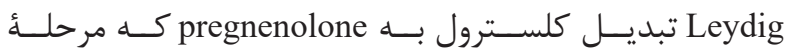

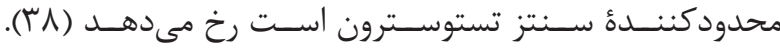
توزيع آناتوميك محدوديك

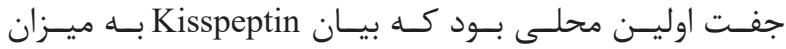

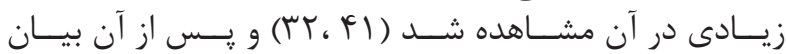

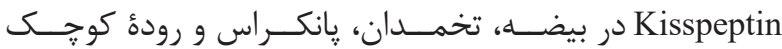

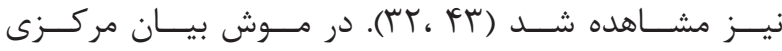

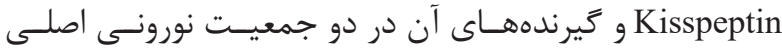

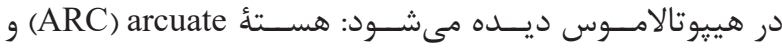

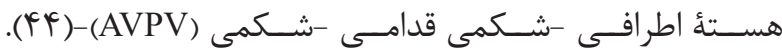

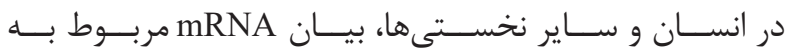

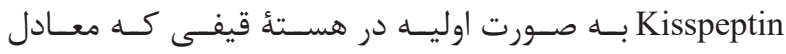

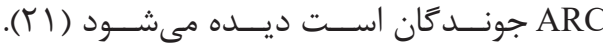

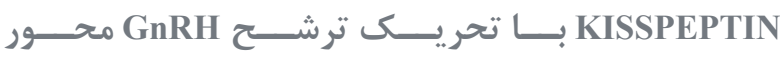

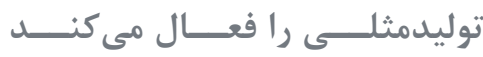

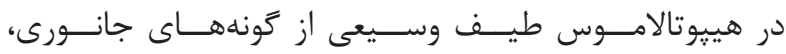

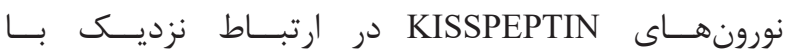

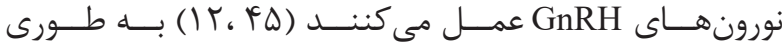

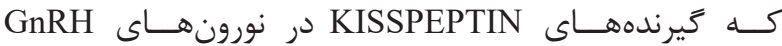

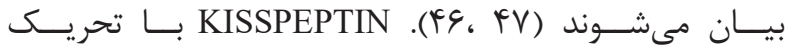

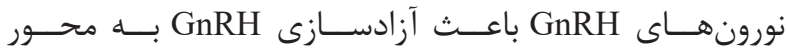

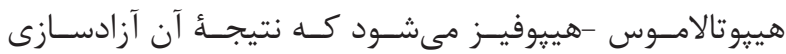

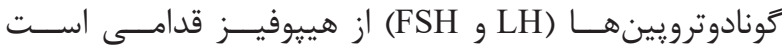

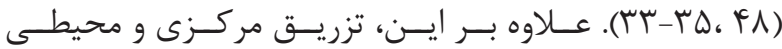

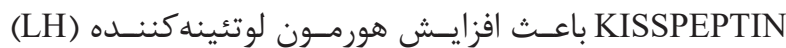

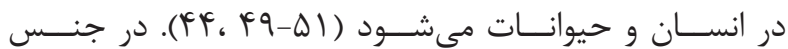

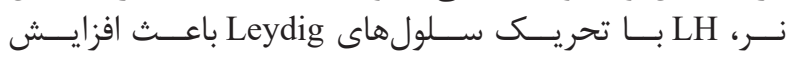

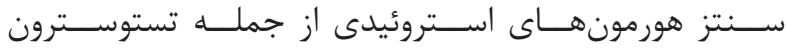

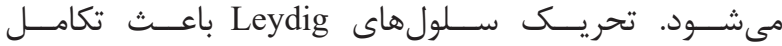

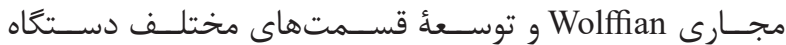

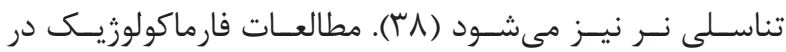

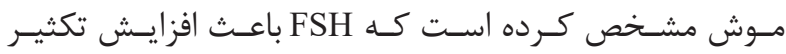

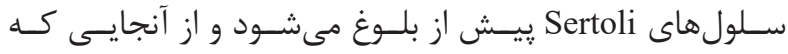

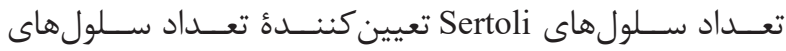

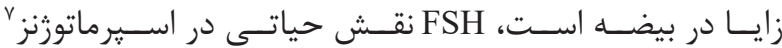

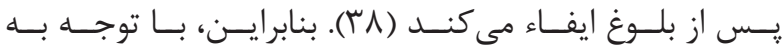

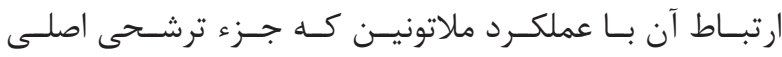

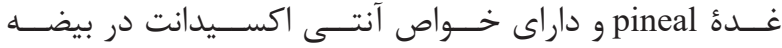

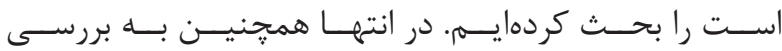

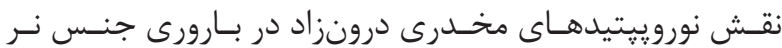

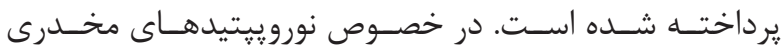

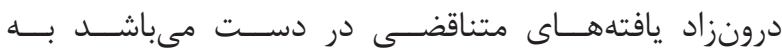

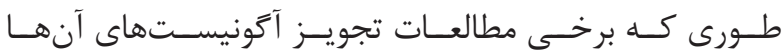

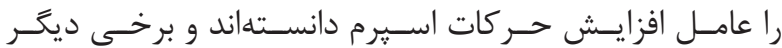

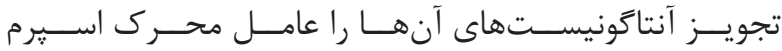

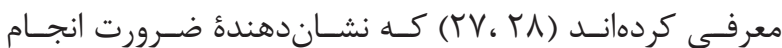

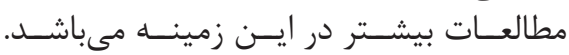

Kisspeptin

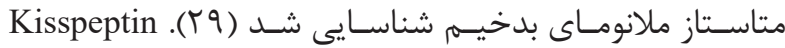

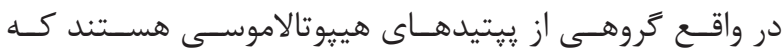

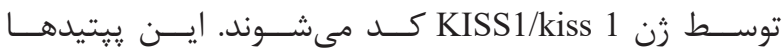

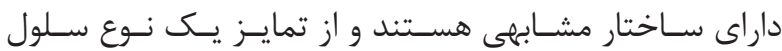

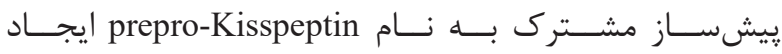

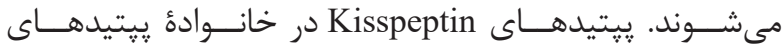

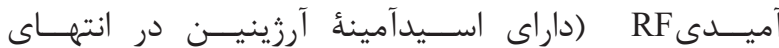

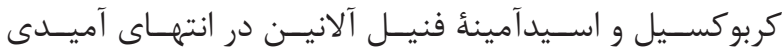

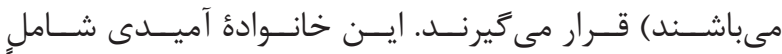

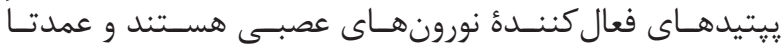

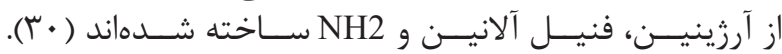

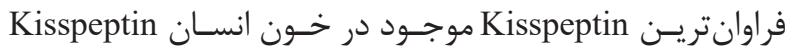

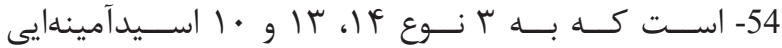

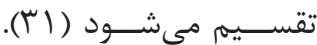

Kisspeptin

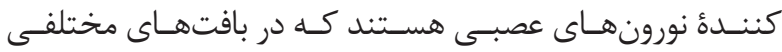

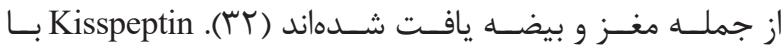

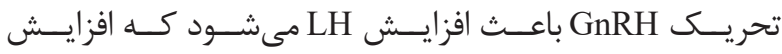

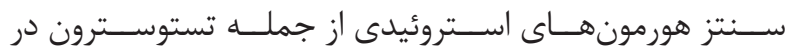

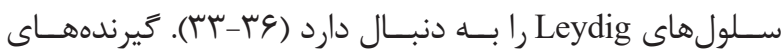

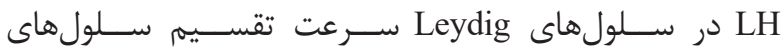

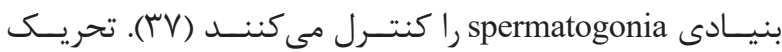

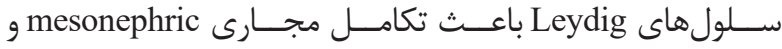

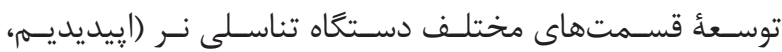

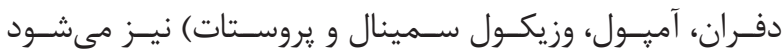

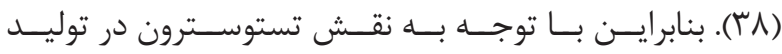

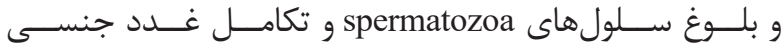

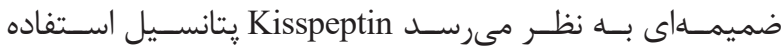

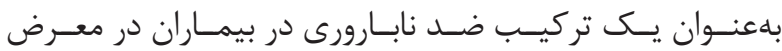

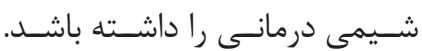

Kيرندهاى Kisspeptin

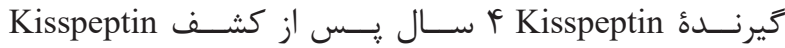

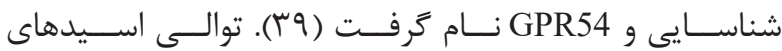

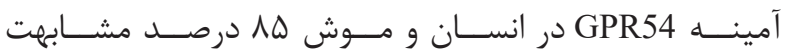




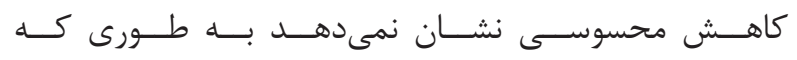

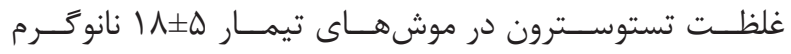

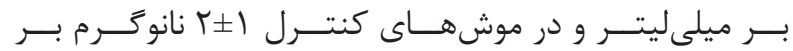

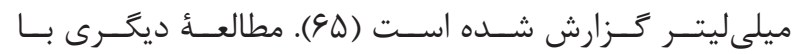

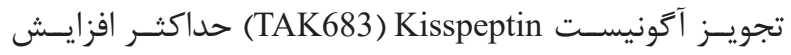

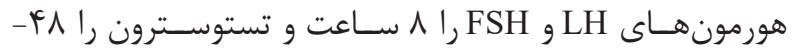

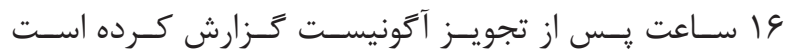

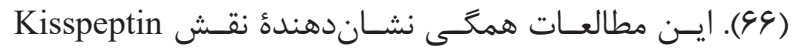

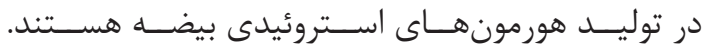

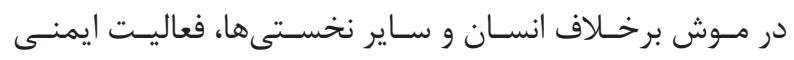

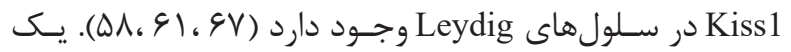

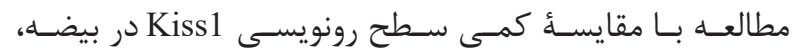

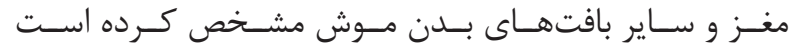

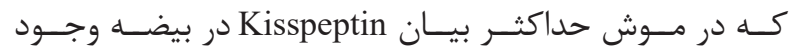

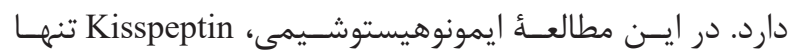

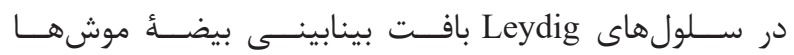

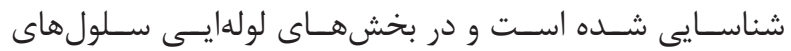
Sertoli

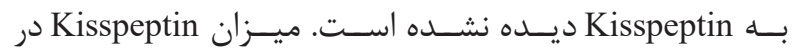

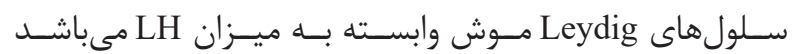

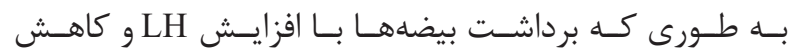

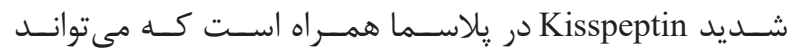

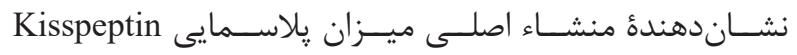

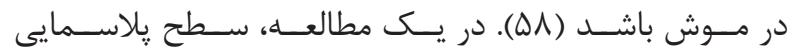

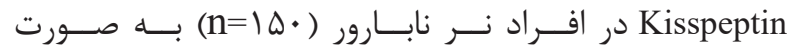

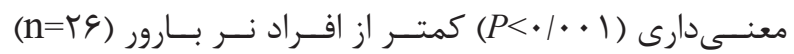

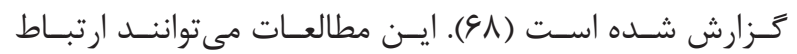

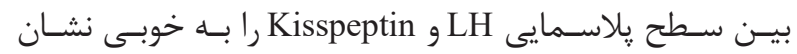

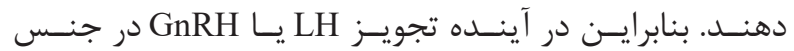

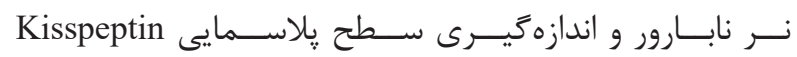

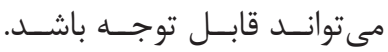

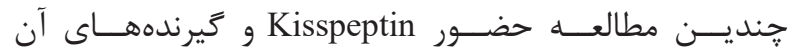

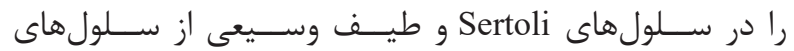

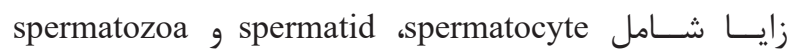

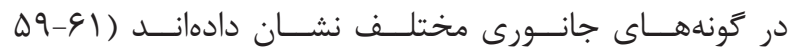

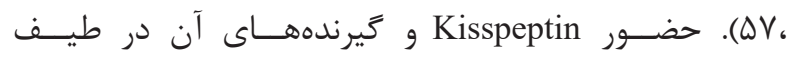

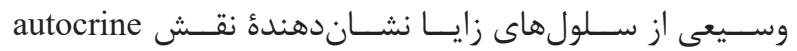

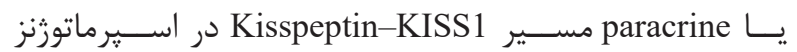

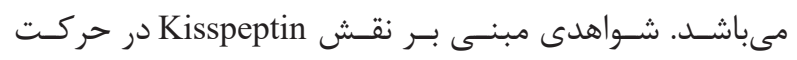

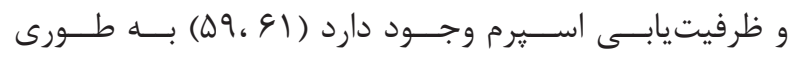

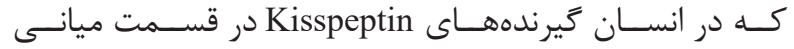

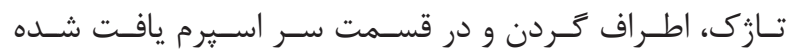

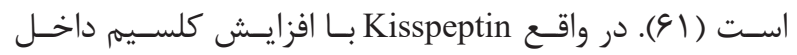

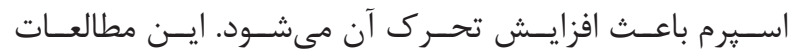

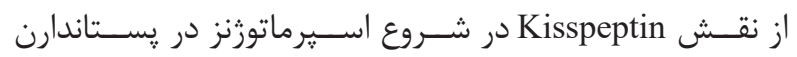

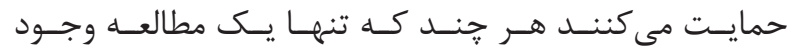

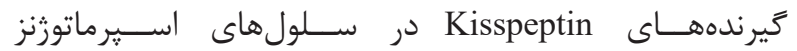

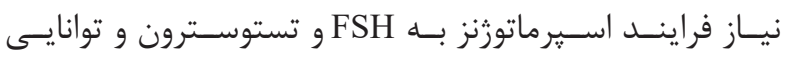
KISSPEPTIN

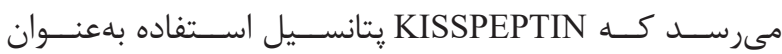

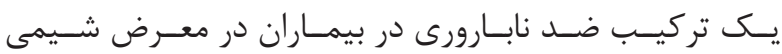

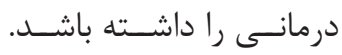

نقشــى حياتــى در شـــروع بلــوغ ايفــاء مى كن

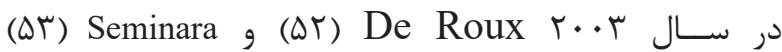

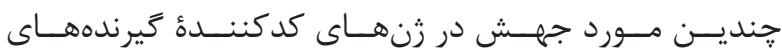
KISSPEPTIN

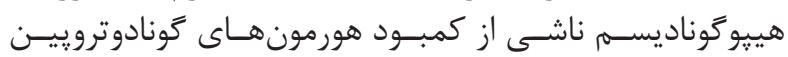

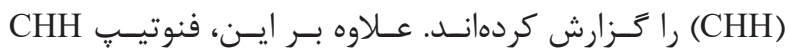

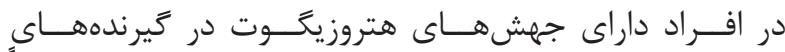
KISSPEPTIN

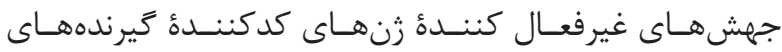

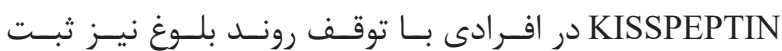
شــده اسـت (ه (ه).

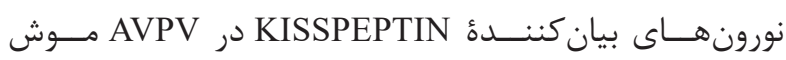

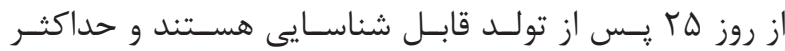

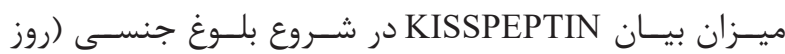

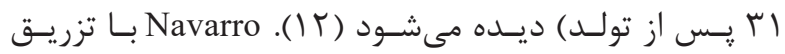

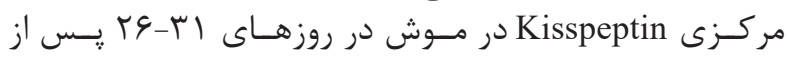

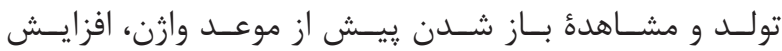

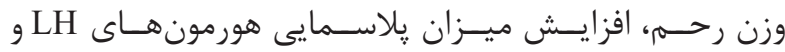

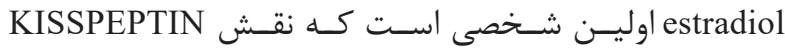

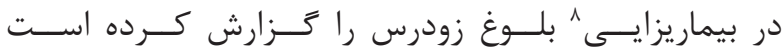

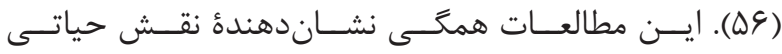
KISSPEPTIN

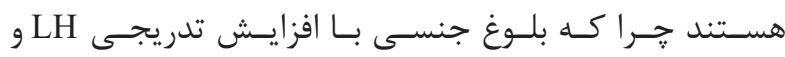

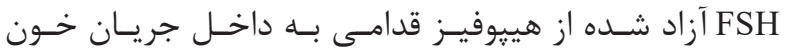

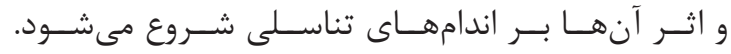
نقش Kisspeptin در دستعاه توليدمثلى جنس نر مطالعـات زيــادى بيــان زنهــــ KISS1/kiss1 در دســــاه

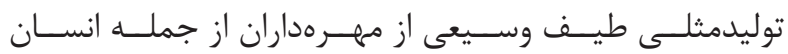

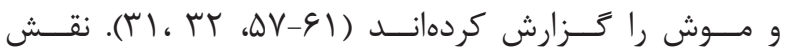

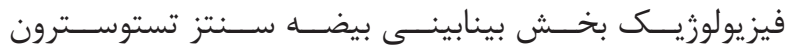

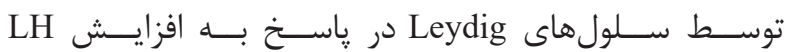

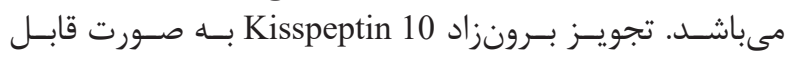

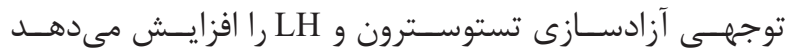

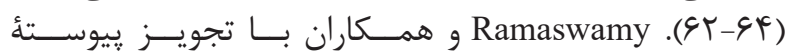
مisspeptin

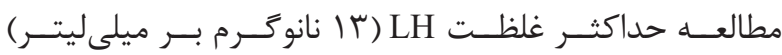

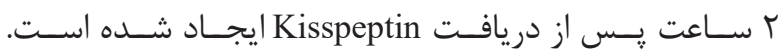

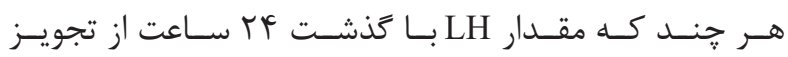
تبهش Kisspeptin

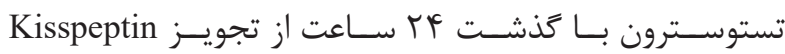




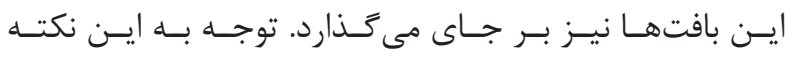

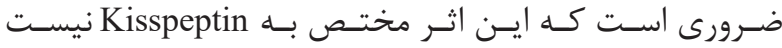

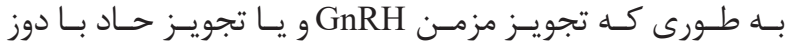

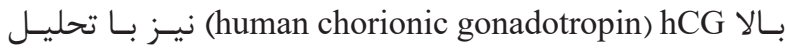

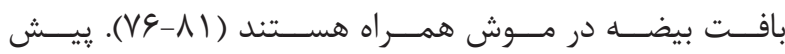

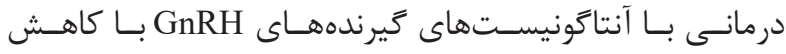

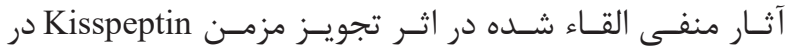

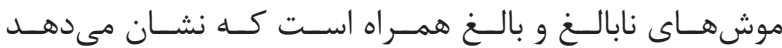

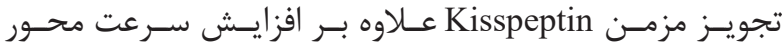

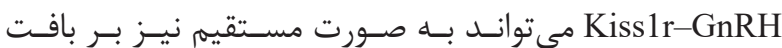

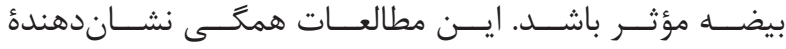

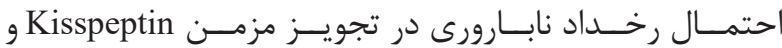

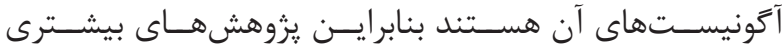

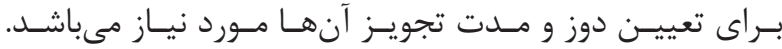

NKB

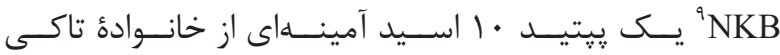

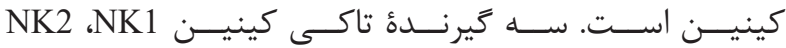

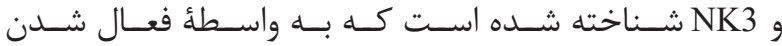

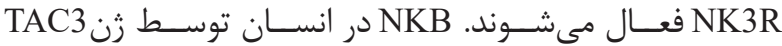

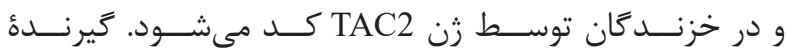

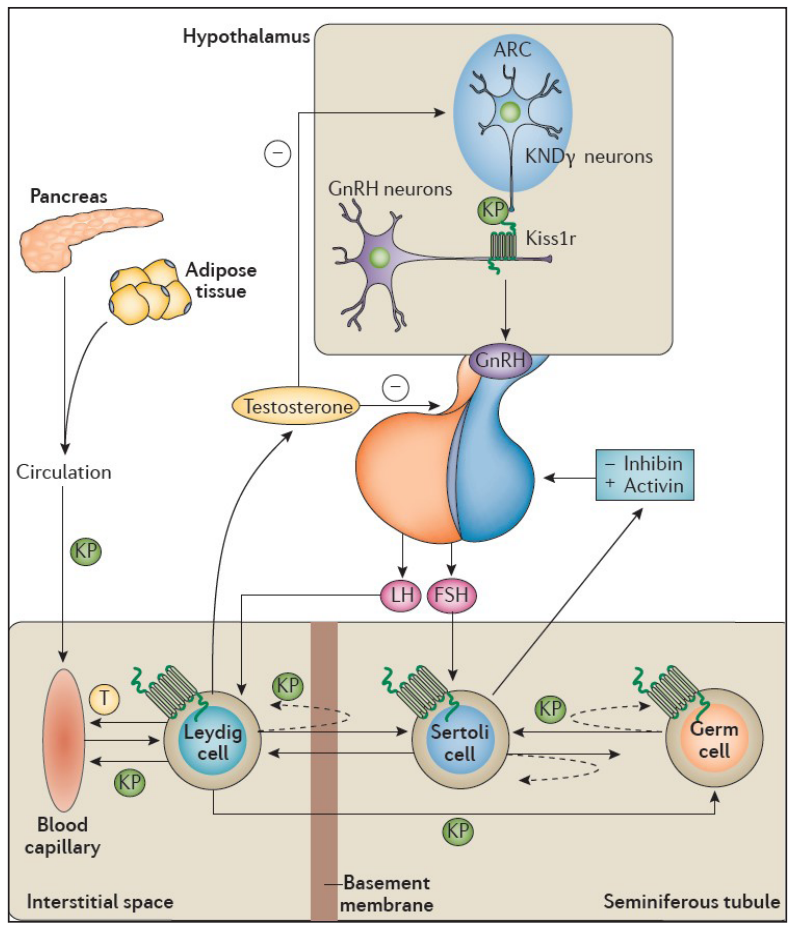

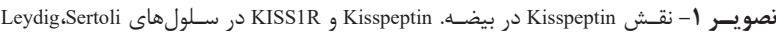

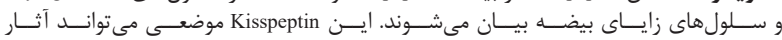

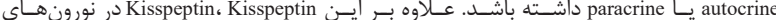

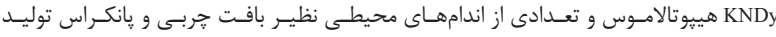

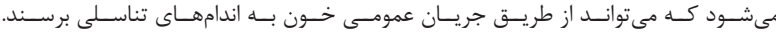

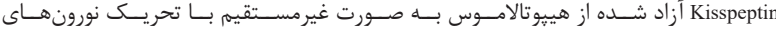

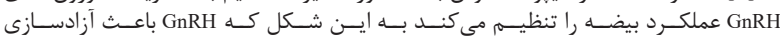

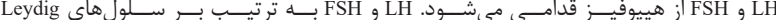

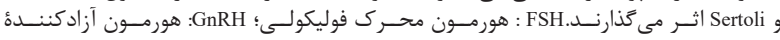

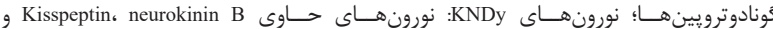

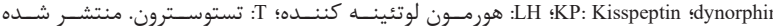

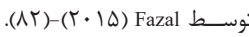

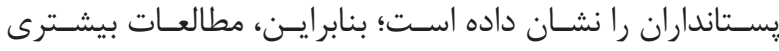

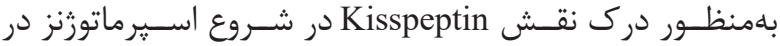

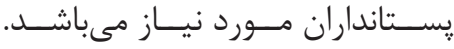
Kisspeptin يتانسيل هاى درمانى:

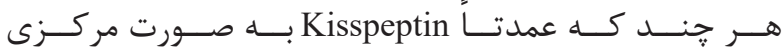

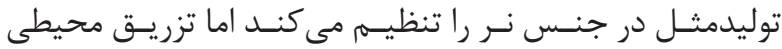

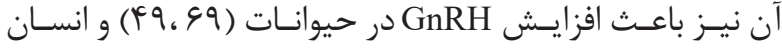

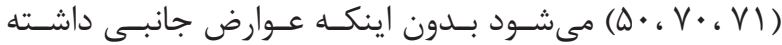

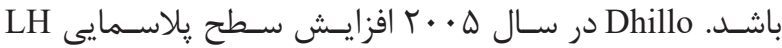

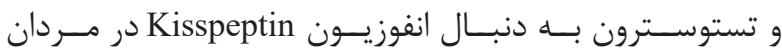

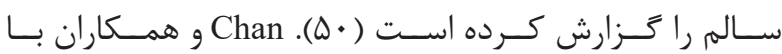

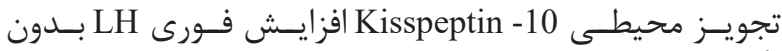

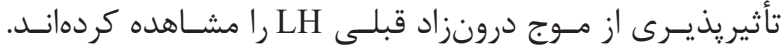

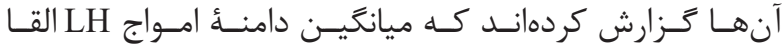

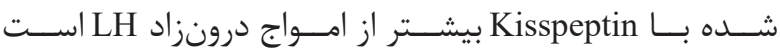

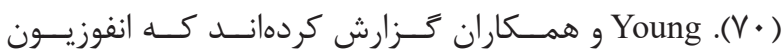

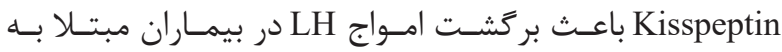

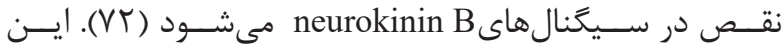

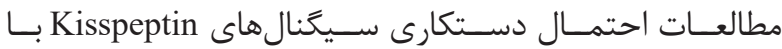

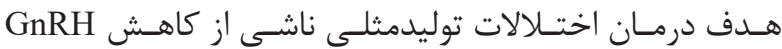

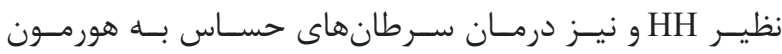

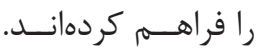

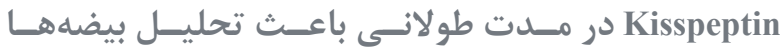
مى شــــود

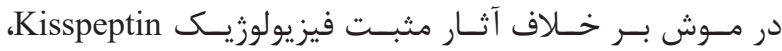

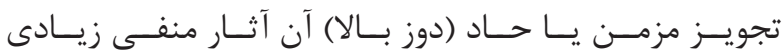

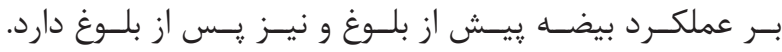

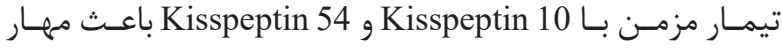

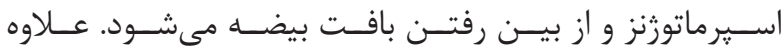

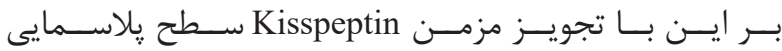

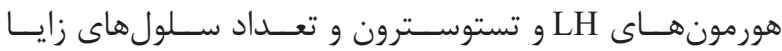

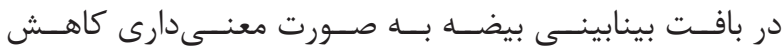

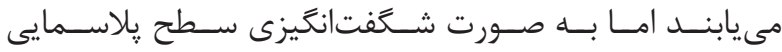

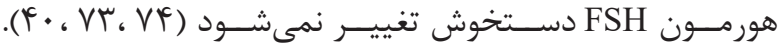

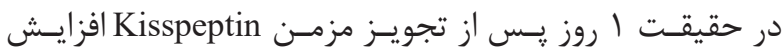

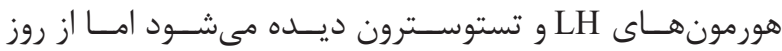

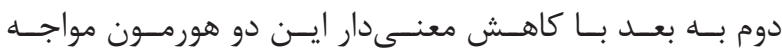

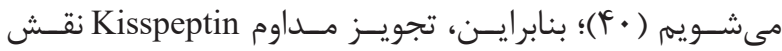

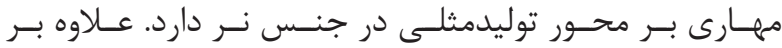

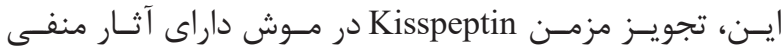

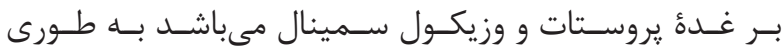

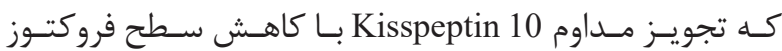

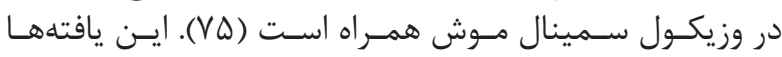

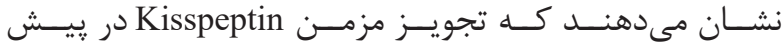

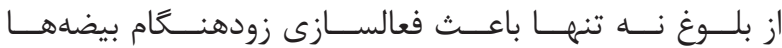

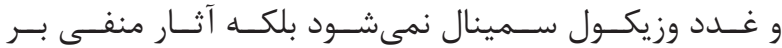

${ }^{9}$ Neurokinin B 


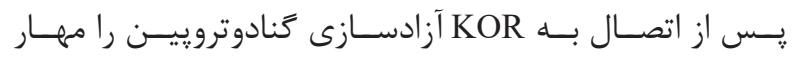

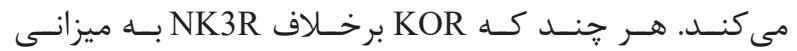

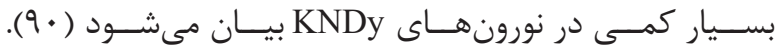

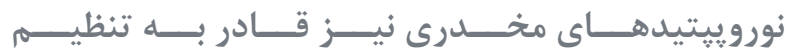

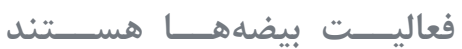

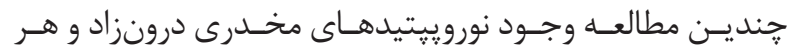

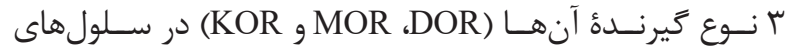

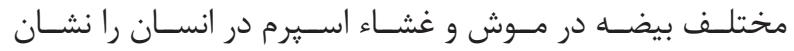

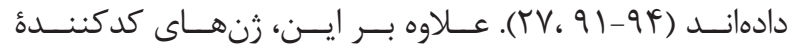

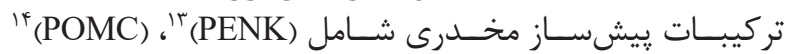

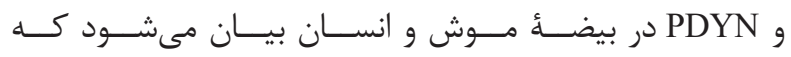

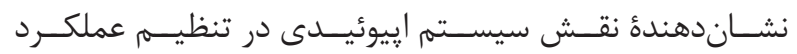

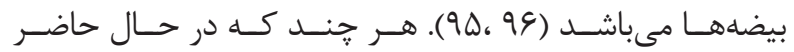

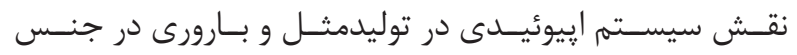

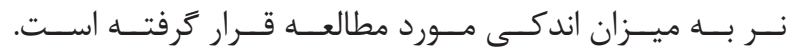

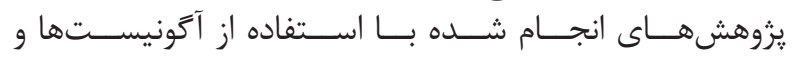

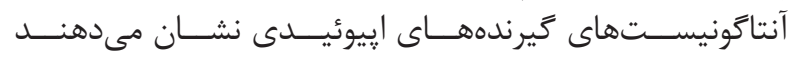

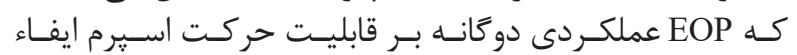

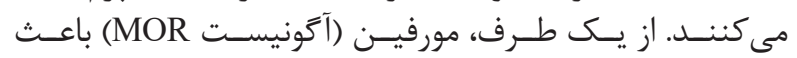

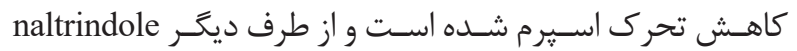

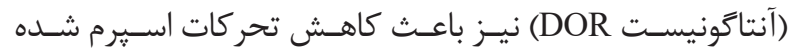

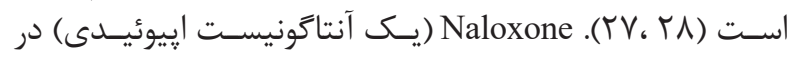

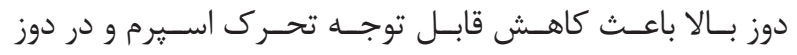

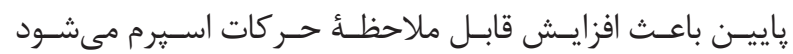

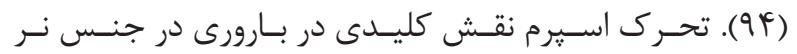

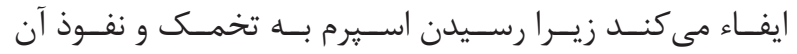

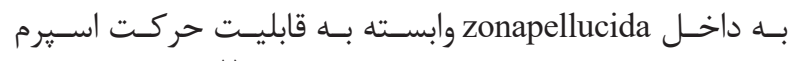

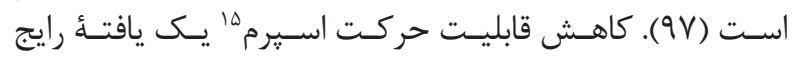

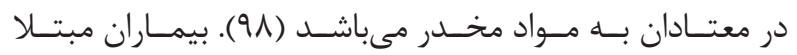

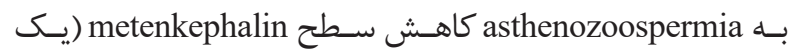

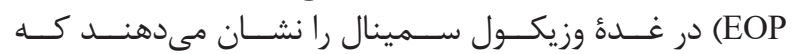

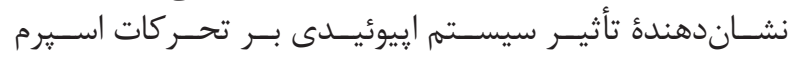

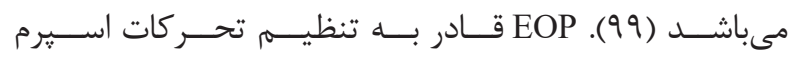

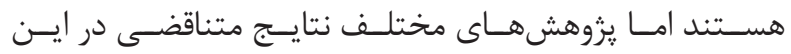

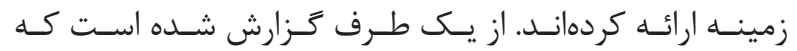

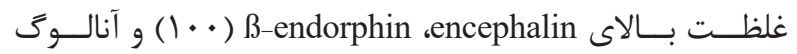

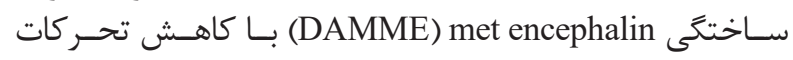

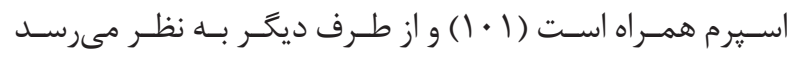

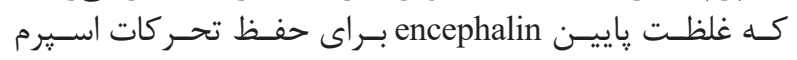

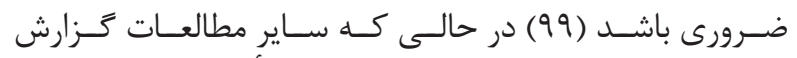

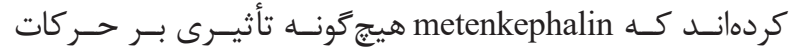

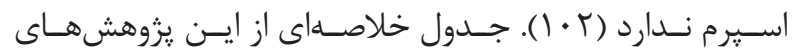

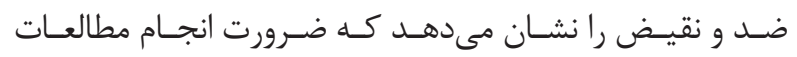

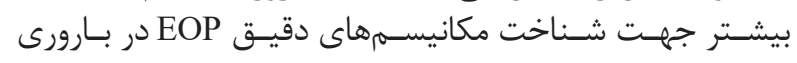

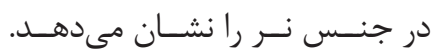

\footnotetext{
${ }^{10}$ Signaling

${ }^{11}$ Pro-dynorphin

${ }^{12}$ Endogenous opioid peptides
}

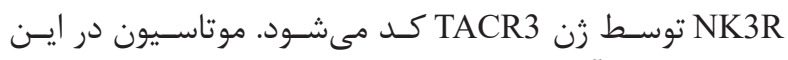

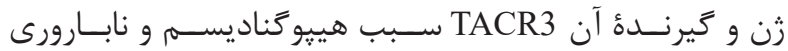

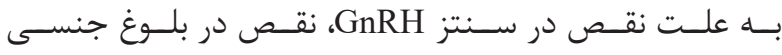

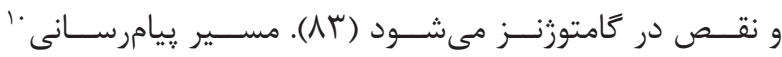
NKB

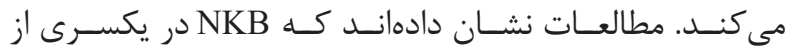

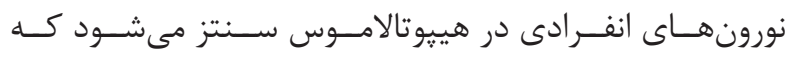

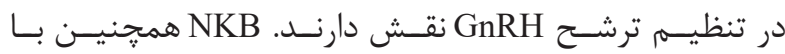

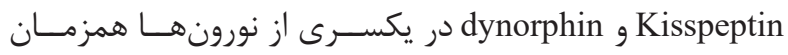

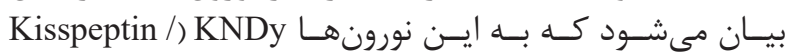
NKB/Dynorphin

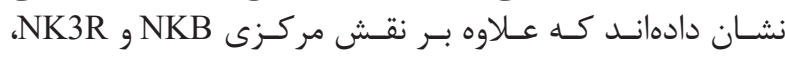

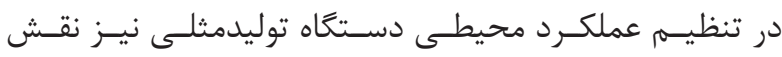

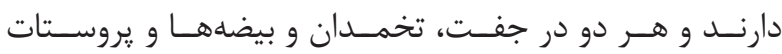

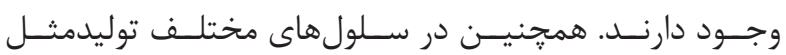

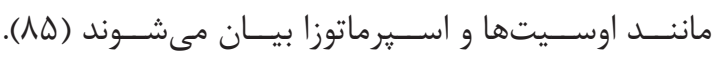

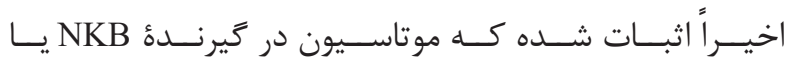

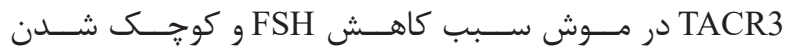

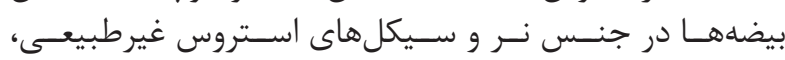

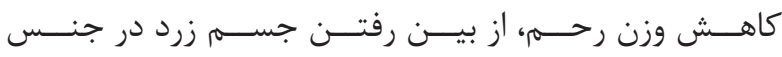

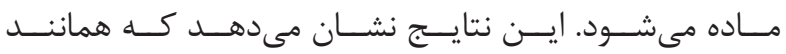

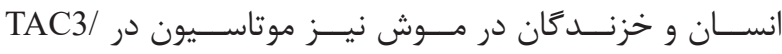

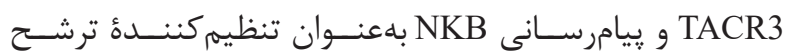

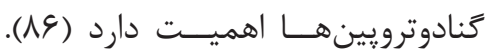

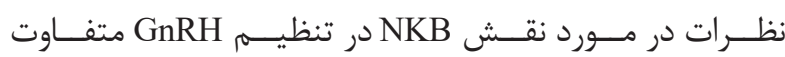

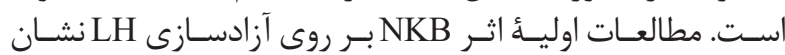

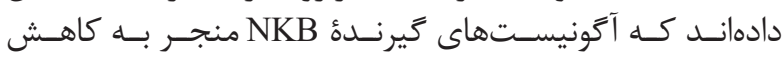

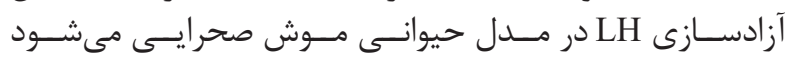

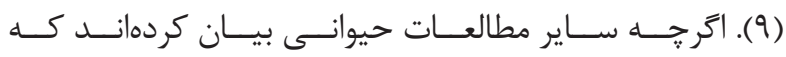

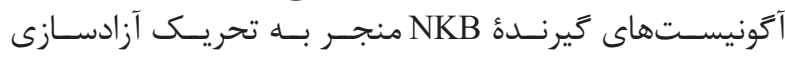

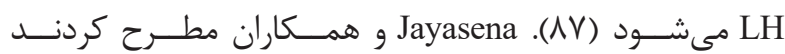

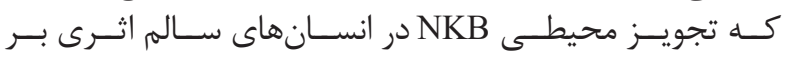

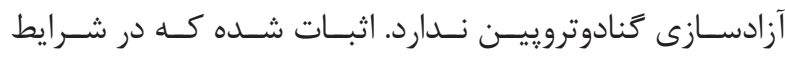

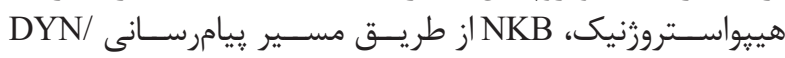

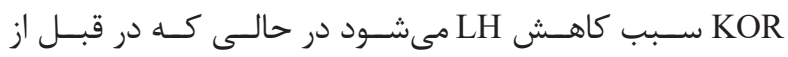

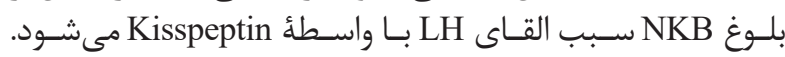

DYN

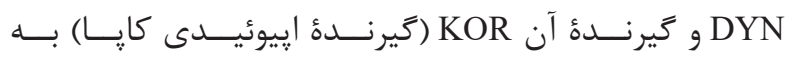

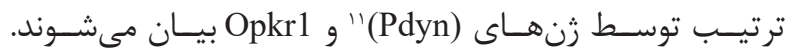

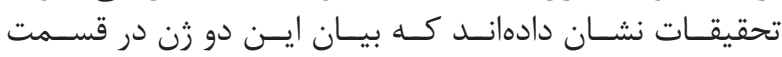

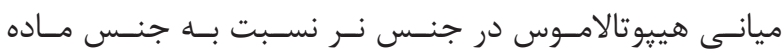

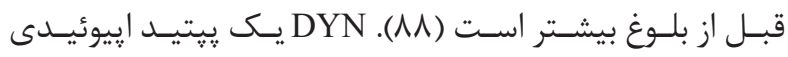

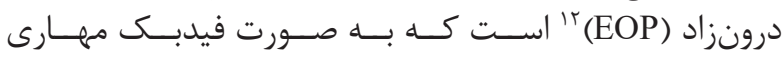

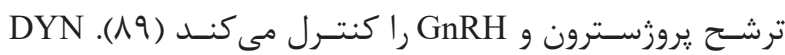

\footnotetext{
${ }^{13}$ Pro-enkephalin

${ }^{14}$ Pro-opiomelanocortin

${ }^{15}$ Asthenozoospermia
} 


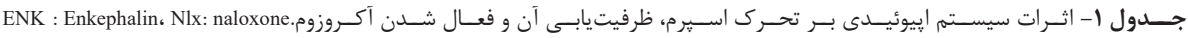

\begin{tabular}{|c|c|c|c|c|}
\hline & حركت & ظرفيت يابى & فعال شدن آكروزوم & منبع \\
\hline$\uparrow[\mathrm{ENK}]$ & كاهش & - & - & $1 \cdots$ \\
\hline$\downarrow[\mathrm{ENK}]$ & ضرورى & - & - & ११ \\
\hline$\beta$-Endorphin & كاهش & - & - & r. \\
\hline DAMME & كاهش & - & كاهش & $1 \cdot 1$ \\
\hline Morphine & كاهش & - & - & tr \\
\hline Naltrindol & كاهش & افزايش & افزايش & th \\
\hline$\uparrow[\mathrm{Nlx}]$ & كاهش & - & - & 94 \\
\hline$\downarrow[\mathrm{Nlx}]$ & افزايش & افزايش & - & $9 f$ \\
\hline Heroin & كاهش & - & - & $9 \wedge$ \\
\hline Methadone & كاهش & - & - & $9 \wedge$ \\
\hline
\end{tabular}

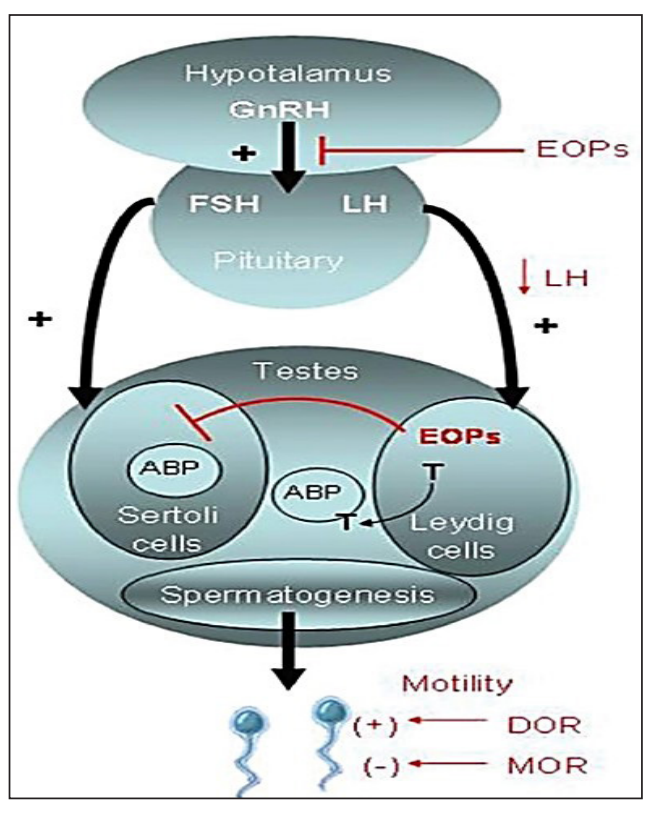

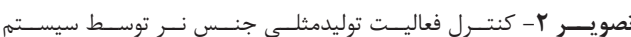

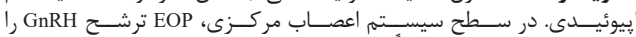

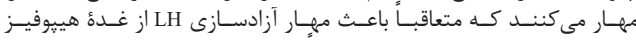

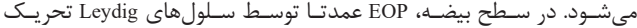

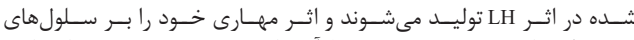

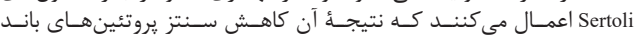

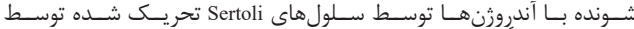

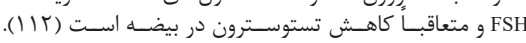

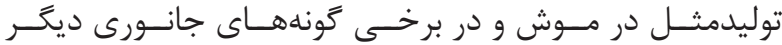

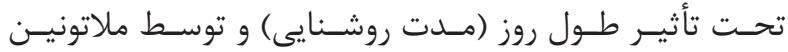

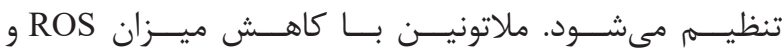

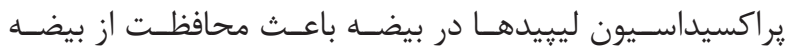

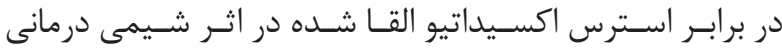

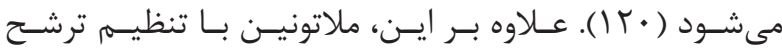

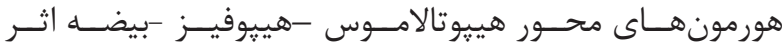

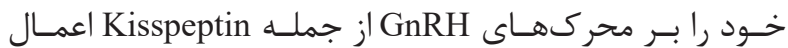

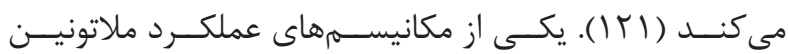

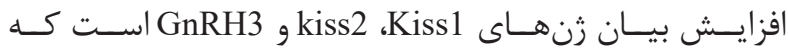

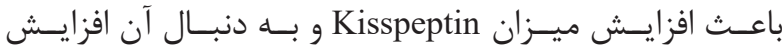

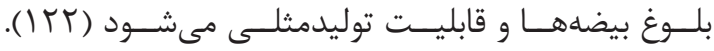

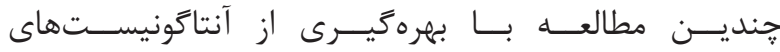

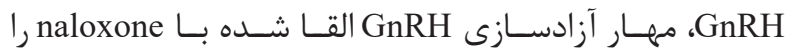

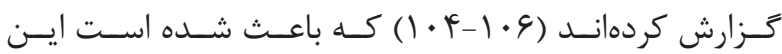

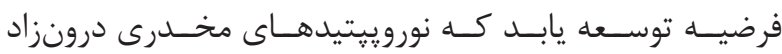

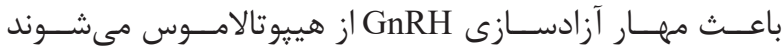

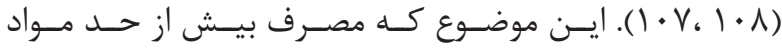

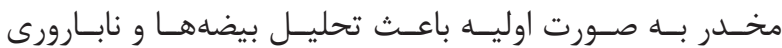

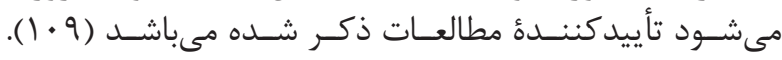

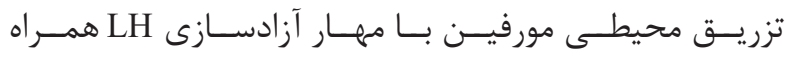

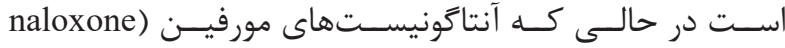

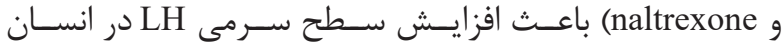

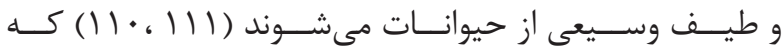

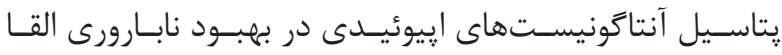

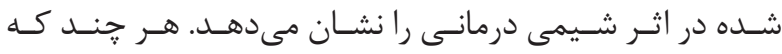

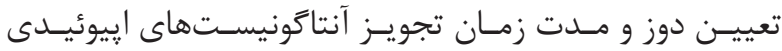

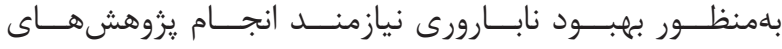

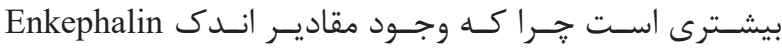

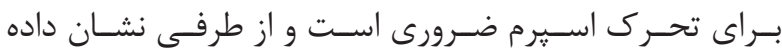

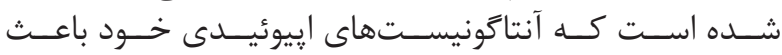

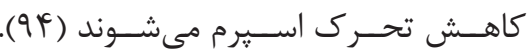

ملاتونين و نوروينيتيدها

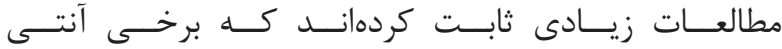

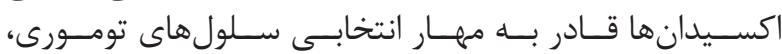

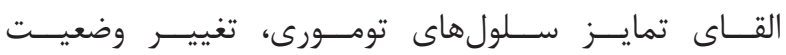

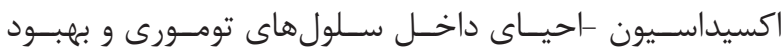

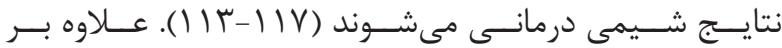

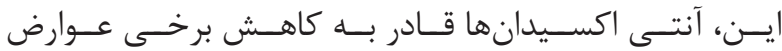

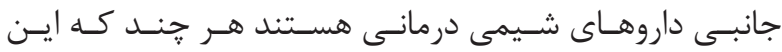

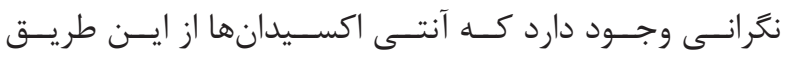

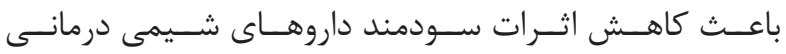

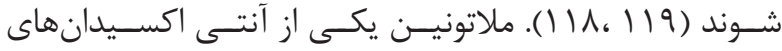

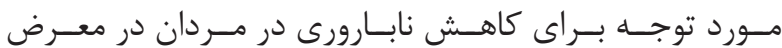

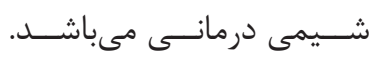




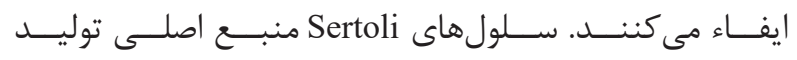
Estrogen

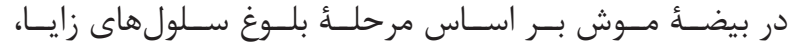

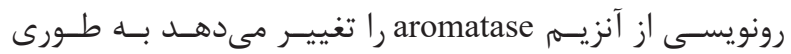

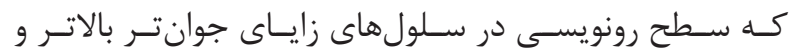

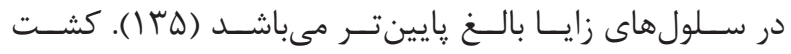

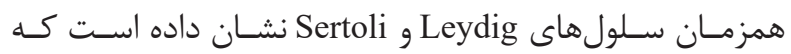

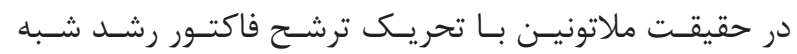

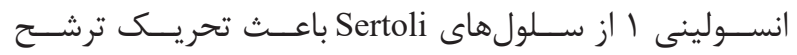

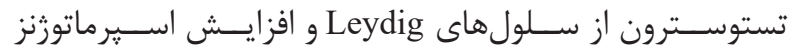

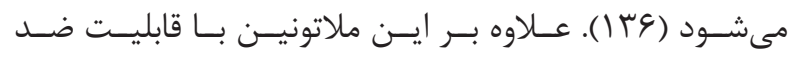

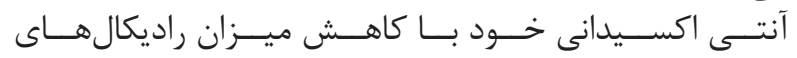

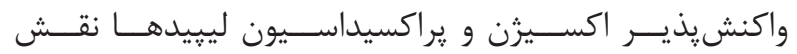

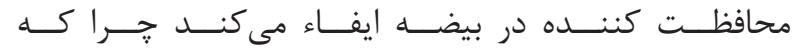

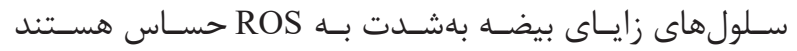

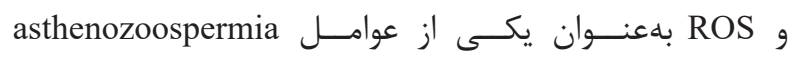

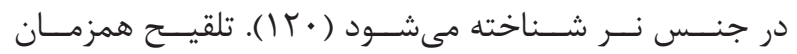

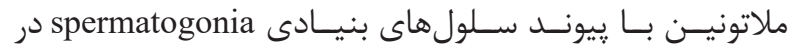

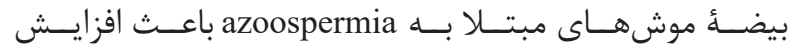

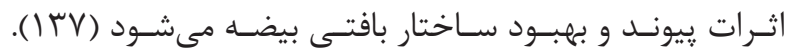

\section{نتيجه}

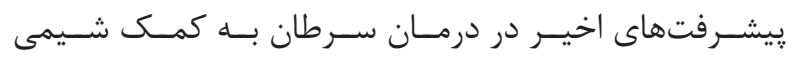

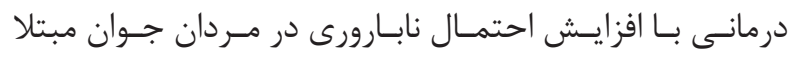

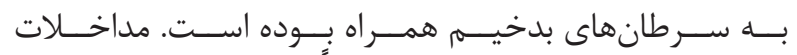

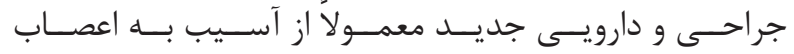

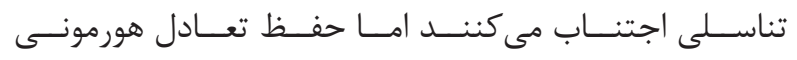

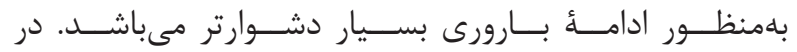

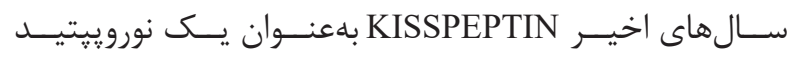

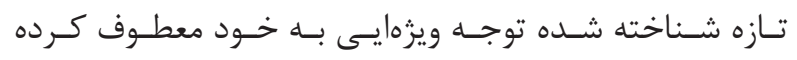

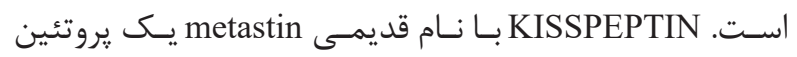

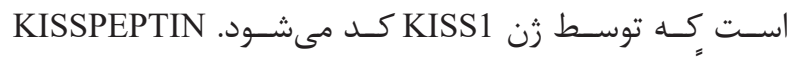

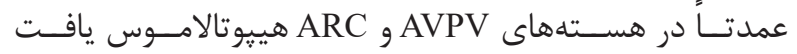

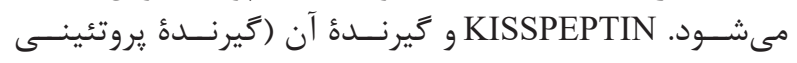

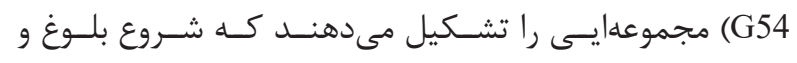

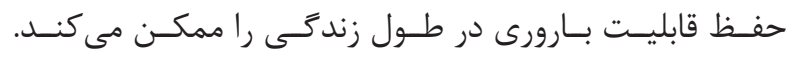

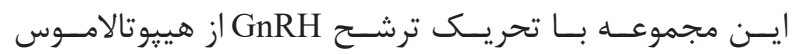

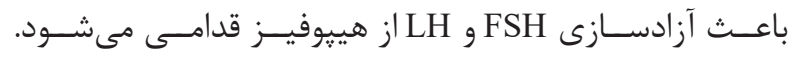

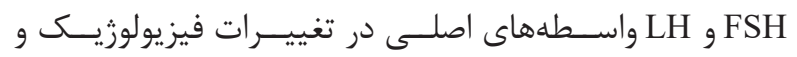

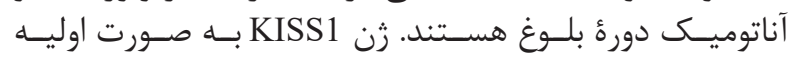

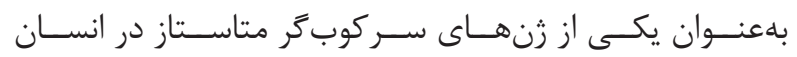

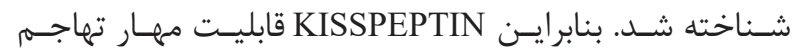

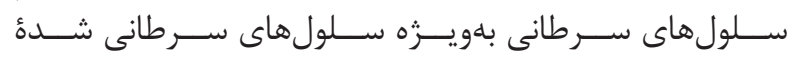

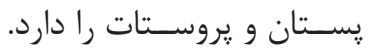

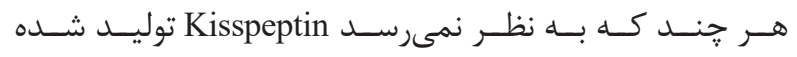

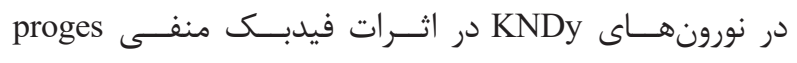

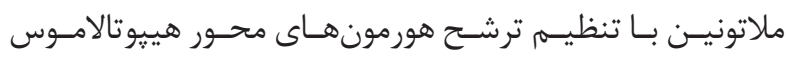

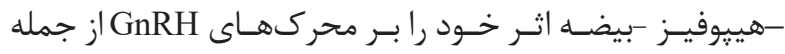
Kisspeptin

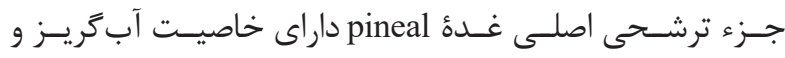

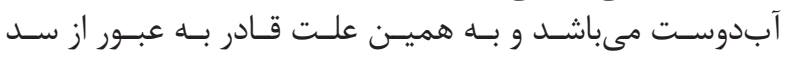

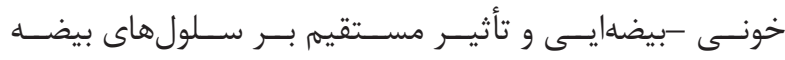

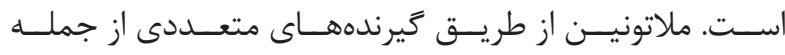

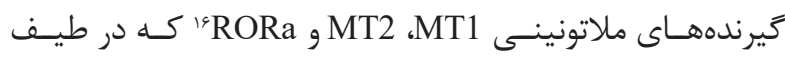

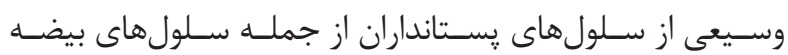

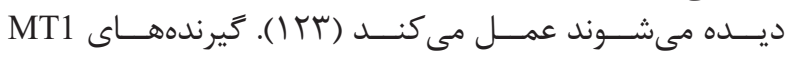

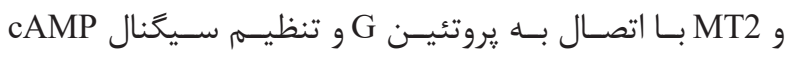

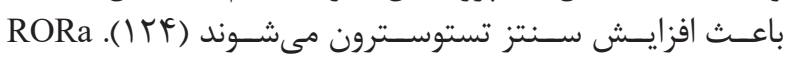

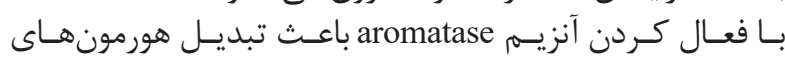

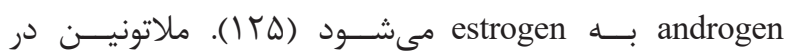

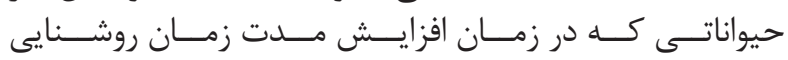

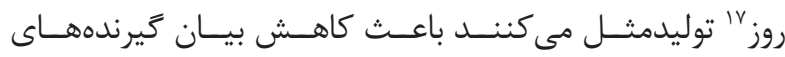

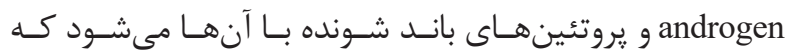

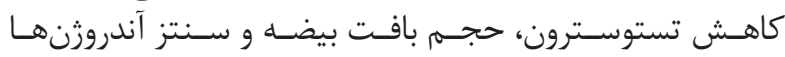

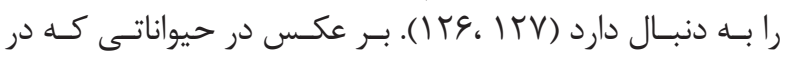

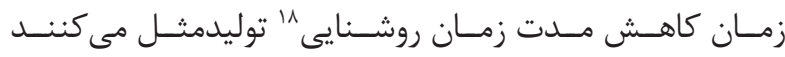

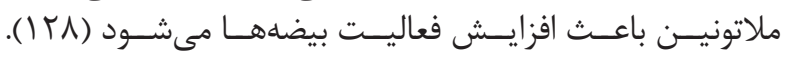

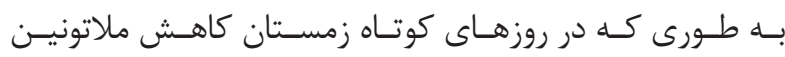

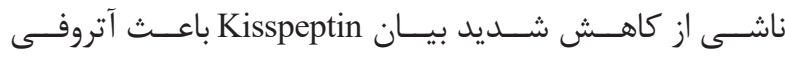

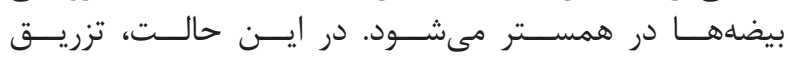

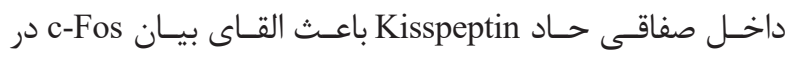

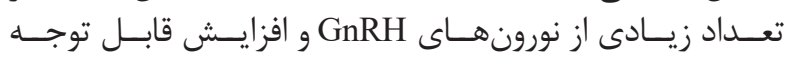

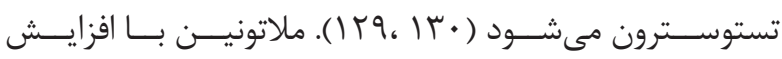

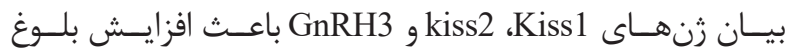

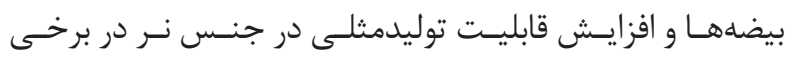

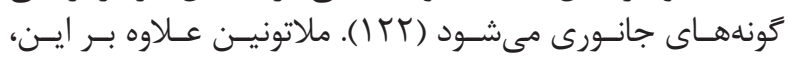

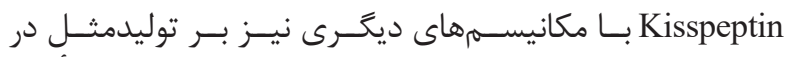

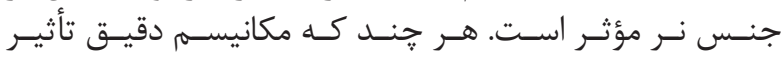

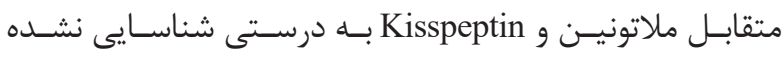

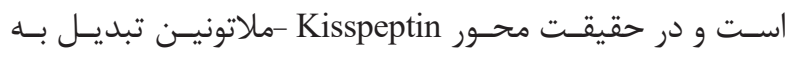

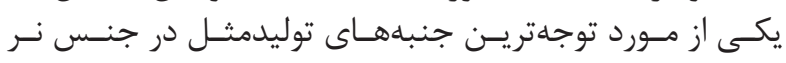

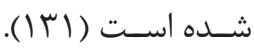

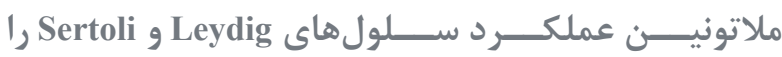
تنظيـــم مكى كنـــــد

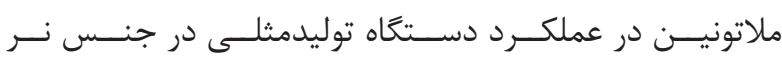

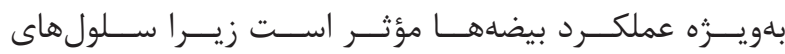

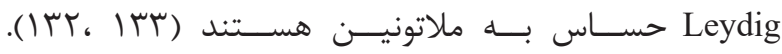

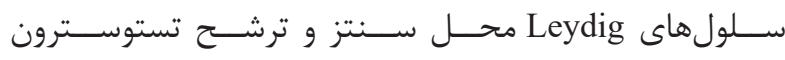

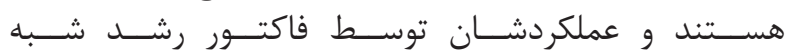

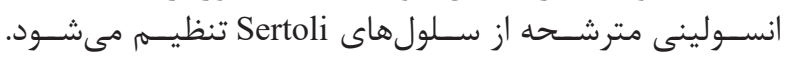

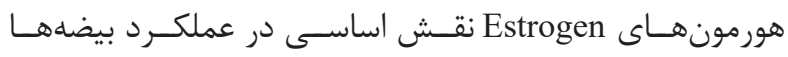

${ }^{16}$ Retinoic acid receptor-related orphan receptor A

${ }^{17}$ Long-day

${ }^{18}$ Short-day 
KNDy

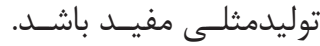

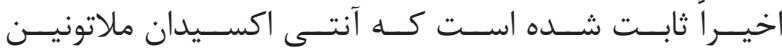

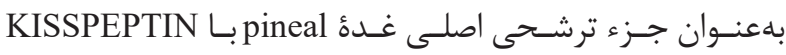

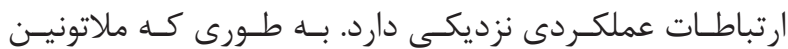

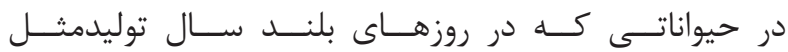

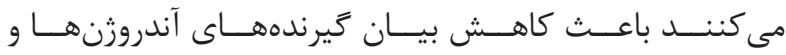

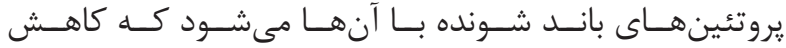

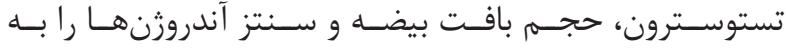

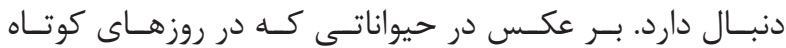

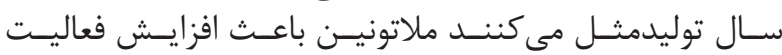

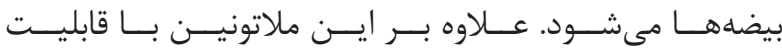

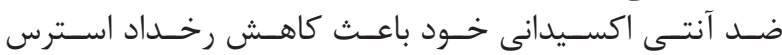

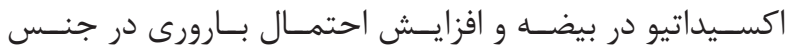

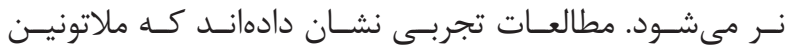

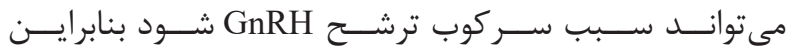

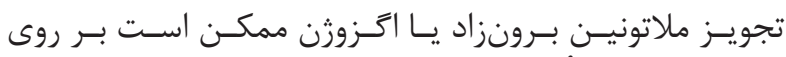

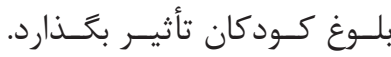

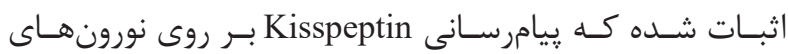

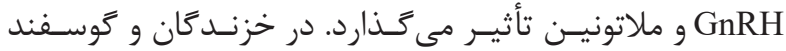

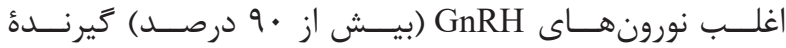

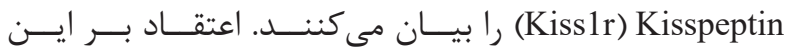

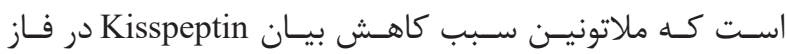

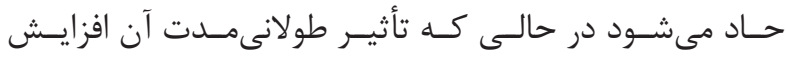

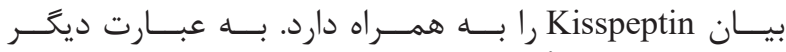

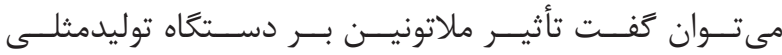

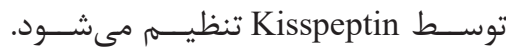

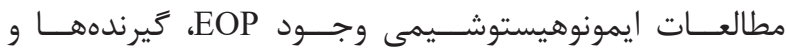

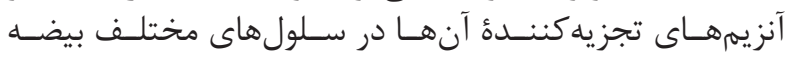

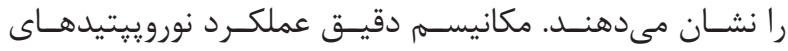

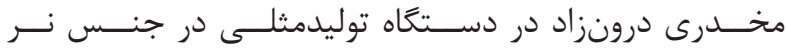

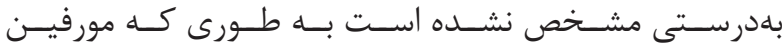

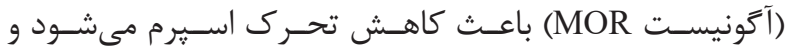

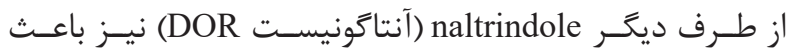

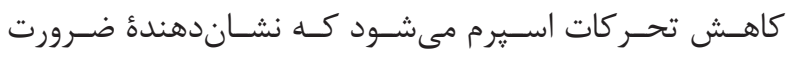

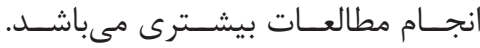

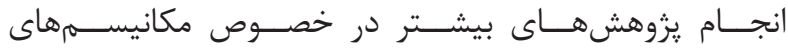

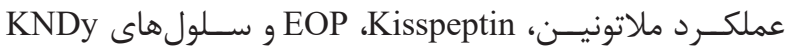

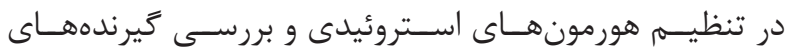

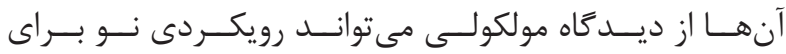

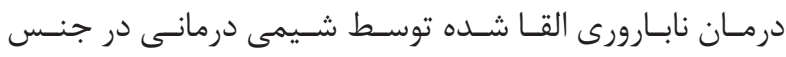

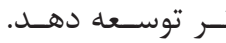

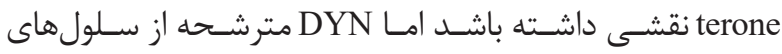

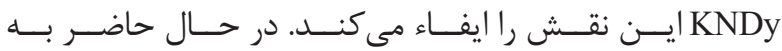

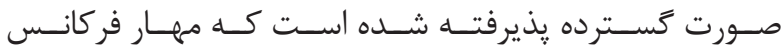

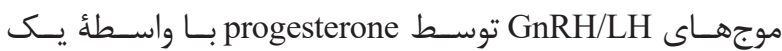

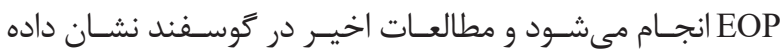

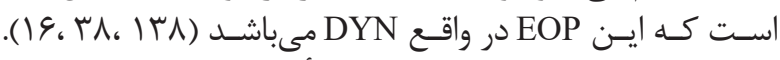

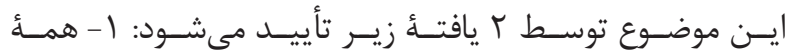

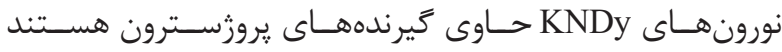

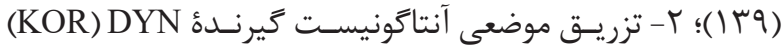

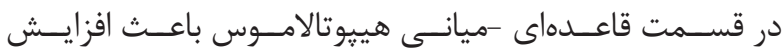

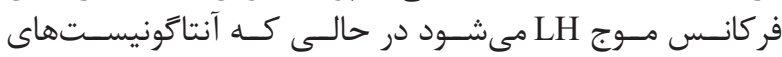

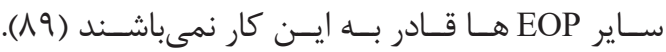

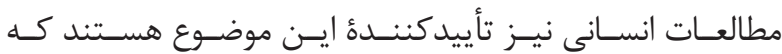

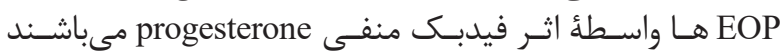

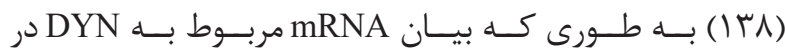

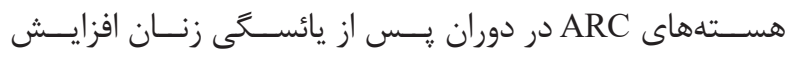

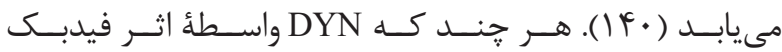

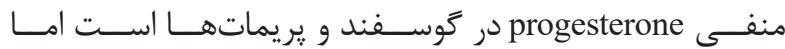

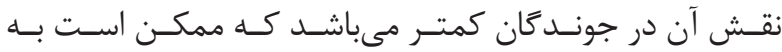

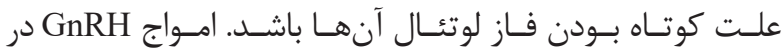

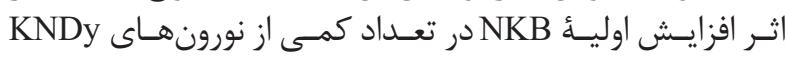

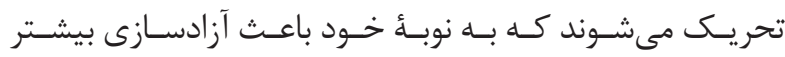

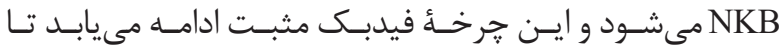

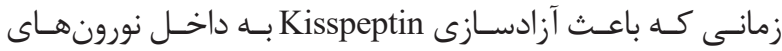

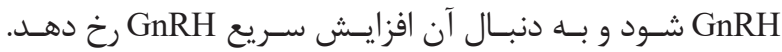

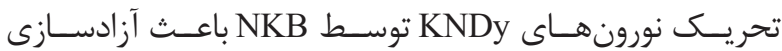

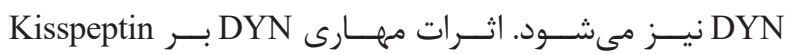

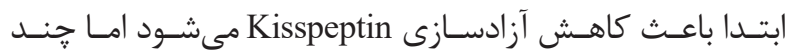

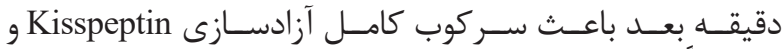

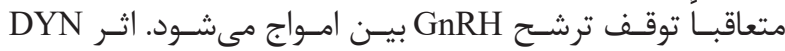

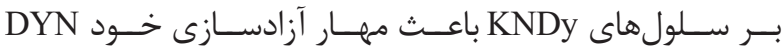

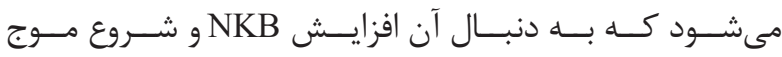

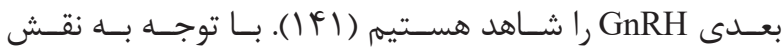

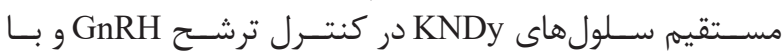

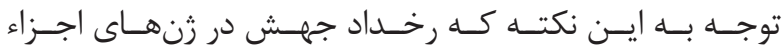

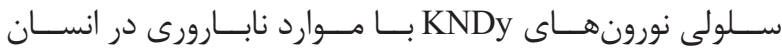

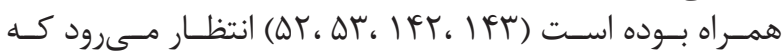

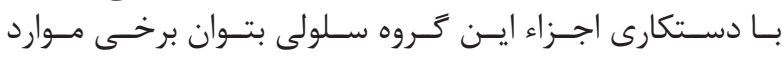

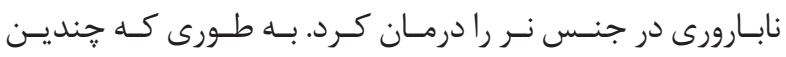

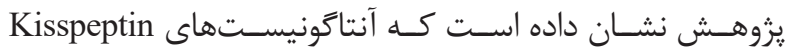

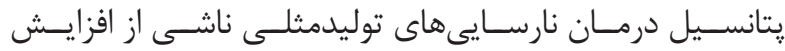

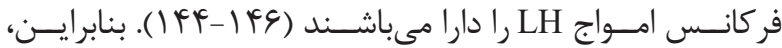

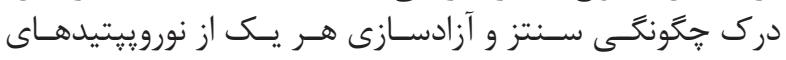


1. Aslam I, Fishel S, Moore H, Dowell K, Thornton S. Fertility preservation of boys undergoing anti-cancer therapy: a review of the existing situation and prospects for the future: opinion. Human Reproduction. 2000; 15(10): 2154-9.

2. Schrader M, HeicappellR, Müller M, Straub B, Miller $\mathrm{K}$. Impact of chemotherapy on male fertility. Onkologie. 2001; 24(4): 326-30.

3. Smith DB, Babaian R. The effects of treatment for cancer on male fertility and sexuality. Cancer Nurs. 1992; 15(4): 271-5.

4. Kuczyk M, Machtens S, Bokemeyer C, Schultheiss D, Jonas U. Sexual function and fertility after treatment of testicular cancer. Curr Opin Urol. 2000; 10(5): 473-7.

5. McCaffrey JA, Bajorin DF. Therapy for good risk germ cell tumors. Semin Oncol. 1998; 25(2): 186-93.

6. Ohl D, Sonksen J. What are the chances of infertility and should sperm be banked? Semin Urol Oncol. 1996; 14(1): 36-44.

7. Goodman RL, Lehman MN, Smith JT, Coolen LM, De Oliveira CV, Jafarzadehshirazi MR, et al. Kisspeptin neurons in the arcuate nucleus of the ewe express both dynorphin A and neurokinin B. Endocrinology. 2007; 148 (12): 5752-60

8. Burke MC, Letts PA, Krajewski SJ, Rance NE. Coexpression of dynorphin and neurokinin B immunoreactivity in the rat hypothalamus: morphologic evidence of interrelated function within the arcuate nucleus. J Comp Neurol. 2006; 498(5): 712-26.

9. Navarro VM, Gottsch ML, Chavkin C, Okamura H, Clifton DK, Steiner RA. Regulation of gonadotropinreleasing hormone secretion by kisspeptin/dynorphin/ neurokinin B neurons in the arcuate nucleus of the mouse. J Neurosci.. 2009; 29(38): 11859-66.

10. Ciofi P, Leroy D, Tramu G. Sexual dimorphism in the organization of the rat hypothalamic infundibular area. Neuroscience. 2006; 141(4): 1731-45.

11. Kinoshita M, Tsukamura H, Adachi S, Matsui H, Uenoyama $\mathrm{Y}$, Iwata $\mathrm{K}$, et al. Involvement of central metastin in the regulation of preovulatory luteinizing hormone surge and estrous cyclicity in female rats. Endocrinology. 2005; 146(10): 4431-6.

12. Clarkson J, Herbison AE. Postnatal development of kisspeptin neurons in mouse hypothalamus; sexual dimorphism and projections to gonadotropin-releasing hormone neurons. Endocrinology. 2006; 147(12):
$5817-25$.

13. Ramaswamy S, Guerriero KA, Gibbs RB, Plant TM. Structural interactions between kisspeptin and GnRH neurons in the mediobasal hypothalamus of the male rhesus monkey (Macaca mulatta) as revealed by double immunofluorescence and confocal microscopy. Endocrinology. 2008; 149(9): 4387-95.

14. Dahl SK, Amstalden M, Coolen L, Fitzgerald M, Lehman M. Dynorphin immunoreactive fibers contact GnRH neurons in the human hypothalamus. Reprod Sci. 2009; 16(8): 781-7.

15. Wakabayashi Y, Nakada T, Murata K, Ohkura S, Mogi K, Navarro VM, et al. Neurokinin B and dynorphin A in kisspeptin neurons of the arcuate nucleus participate in generation of periodic oscillation of neural activity driving pulsatile gonadotropin-releasing hormone secretion in the goat. J Neurosci. 2010; 30(8): 3124-32.

16. Karsch FJ. Central actions of ovarian steroids in the feedback regulation of pulsatile secretion of luteinizing hormone. Annu Rev Physiol. 1987; 49(1): 365-82.

17. Oakley AE, Clifton DK, Steiner RA. Kisspeptin signaling in the brain. Endocr Rev. 2009; 30(6): 713-43.

18. Smith JT, Cunningham MJ, Rissman EF, Clifton DK, Steiner RA. Regulation of Kiss1 gene expression in the brain of the female mouse. Endocrinology. 2005; 146(9): 3686-92.

19. Smith JT, Popa SM, Clifton DK, Hoffman GE, Steiner RA. Kiss1 neurons in the forebrain as central processors for generating the preovulatory luteinizing hormone surge. J Neurosci. 2006; 26(25): 6687-94.

20. Smith JT, Clay CM, Caraty A, Clarke IJ. KiSS1 messenger ribonucleic acid expression in the hypothalamus of the ewe is regulated by sex steroids and season. Endocrinology. 2007; 148(3): 1150-7.

21. Rometo AM, Krajewski SJ, Lou Voytko M, Rance NE. Hypertrophy and increased kisspeptin gene expression in the hypothalamic infundibular nucleus of postmenopausal women and ovariectomized monkeys. J Clin Endocrinol Metab. 2007; 92(7): 2744-50.

22. Navarro VM, Tena-Sempere M. Neuroendocrine control by kisspeptins: role in metabolic regulation of fertility. Nat Rev Endocrinol. 2012; 8(1): 40-53.

23. Skorupskaite K, George JT, Anderson RA. The kisspeptin-GnRH pathway in human reproductive health and disease. Hum Reprod Update. 2014; 20(4): 485-500. 
24. Ko EY, Sabanegh Jr ES, Agarwal A. Male infertility testing: reactive oxygen species and antioxidant capacity. Fertil Steril. 2014; 102(6): 1518-27.

25. Frungieri M, Calandra R, Rossi S. Local actions of melatonin in somatic cells of the testis. Int J Mol Sci. 2017; 18(6): 1170. doi: 10.3390/ijms18061170.

26. Alvarado MV, Carrillo M, Felip A. Melatonininduced changes in kiss/gnrh gene expression patterns in the brain of male sea bass during spermatogenesis. Comp Biochem Physiol A Mol Integr Physiol. 2015; 185: 69-79.

27. Agirregoitia E, Valdivia A, Carracedo A, Casis L, Gil J, Subiran N, et al. Expression and Localization of $\delta$-, $\kappa$-, and $\mu$-opioid receptors in human spermatozoa and implications for sperm motility. J Clin Endocrinol Metab. 2006; 91(12): 4969-75.

28. Albrizio M, Lacalandra GM, Micera E, Guaricci AC, Nicassio M, Zarrilli A. Delta opioid receptor on equine sperm cells: subcellular localization and involvement in sperm motility analyzed by computer assisted sperm analyzer (CASA). Reprod Biol Endocrinol. 2010; 8(1):78. doi: 10.1186/1477-7827-8-78.

29. Lee J-H, Miele ME, Hicks DJ, Phillips KK, Trent JM, Weissman BE, et al. KiSS-1, a novel human malignant melanoma metastasis-suppressor gene. JNCI. 1996; 88(23): 1731-7.

30. Clements MK, McDonald TP, Wang R, Xie G, O'Dowd BF, George SR, et al. FMRFamide-related neuropeptides are agonists of the orphan G-proteincoupled receptor GPR54. Biochem Biophys Res Commun. 2001; 284(5): 1189-93.

31. Kotani M, Detheux M, Vandenbogaerde A, Communi D, Vanderwinden J-M, Le Poul E, et al. The metastasis suppressor gene KiSS-1 encodes kisspeptins, the natural ligands of the orphan $\mathrm{G}$ protein-coupled receptor GPR54. J Biol Chem. 2001; 276(37): 34631-6.

32. Ohtaki T, Shintani Y, Honda S, Matsumoto H, Hori A, Kanehashi K, et al. Metastasis suppressor gene KiSS-1 encodes peptide ligand of a G-protein-coupled receptor. Nature. 2001; 411(6837): 613-7.

33. Liu X, Lee K, Herbison AE. Kisspeptin excites gonadotropin-releasing hormone neurons through a phospholipase $\mathrm{C} /$ calcium-dependent pathway regulating multiple ion channels. Endocrinology. 2008; 149(9): 4605-14.

34. Irwig MS, Fraley GS, Smith JT, Acohido BV, Popa SM, Cunningham MJ, et al. Kisspeptin activation of gonadotropin releasing hormone neurons and regulation of KiSS-1 mRNA in the male rat. Neuroendocrinology. 2004; 80(4): 264-72.

35. Novaira HJ, Ng Y, Wolfe A, Radovick S. Kisspeptin increases GnRH mRNA expression and secretion in GnRH secreting neuronal cell lines. Mol Cell Endocrinol. 2009; 311(1-2): 126-34.

36. Fowler PA, Anderson RA, Saunders PT, Kinnell H, Mason JI, Evans DB, et al. Development of steroid signaling pathways during primordial follicle formation in the human fetal ovary. J Clin Endocrinol Metab. 2011; 96(6): 1754-62.

37. Courot M, Ortavant R. Endocrine control of spermatogenesis in the ram. J Reprod Fertil Suppl. 1981; 30: $47-60$.

38. Neill JD. Knobil and Neill's physiology of reproduction: Academic Press; 2005.

39. Gottsch ML, Clifton DK, Steiner RA. From KISS1 to kisspeptins: an historical perspective and suggested nomenclature. Peptides. 2009; 30(1): 4-9.

40. Thompson EL, MurphyKG, Patterson M, Bewick GA, Stamp GW, Curtis A, et al. Chronic subcutaneous administration of kisspeptin-54 causes testicular degeneration in adult male rats. Am J Physiol Endocrinol Metab. 2006; 291(5): 1074-82.

41. Muir AI, Chamberlain L, Elshourbagy NA, Michalovich D, Moore DJ, Calamari A, et al. AXOR12, a novel human $\mathrm{G}$ protein-coupled receptor, activated by the peptide KiSS-1. J Biol Chem. 2001; 276(31): 28969-75.

42. Constantin S, Caligioni CS, Stojilkovic S, Wray S. Kisspeptin-10 facilitates a plasma membrane-driven calcium oscillator in gonadotropin-releasing hormone-1 neurons. Endocrinology. 2008; 150(3): 1400-12.

43. Gaytan F, Gaytan M, Castellano JM, Romero M, Roa J, Aparicio B, et al. Kiss-1 in the mammalian ovary: distribution of kisspeptin in human and marmoset, and alterations in kiss-1 mRNA levels in a rat model of ovulatory dysfunction. Am J Physiol Endocrinol Metab. 2009; 296(3): 520-31.

44. Gottsch M, Cunningham M, Smith J, Popa S, Acohido B, Crowley W, et al. A role for kisspeptins in the regulation of gonadotropin secretion in the mouse. Endocrinology. 2004; 145(9): 4073-7.

45. Rance NE, Young III WS, McMullen NT. Topography of neurons expressing luteinizing hormone-releasing hormone gene transcripts in the human hypothalamus and basal forebrain. J Comp Neurol. 1994; 339(4): 573 86. 


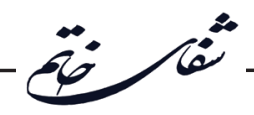

46. d'Anglemont de Tassigny X, Fagg LA, Carlton MB, Colledge WH. Kisspeptin can stimulate gonadotropinreleasing hormone $(\mathrm{GnRH})$ release by a directaction at GnRH nerve terminals. Endocrinology. 2008; 149(8): 3926-32.

47. Herbison AE, d'Anglemont de Tassigny X, Doran J, Colledge WH. Distribution and postnatal development of Gpr54 gene expression in mouse brain and gonadotropin-releasing hormone neurons. Endocrinology. 2010; 151(1): 312-21.

48. Messager S, Chatzidaki EE, Ma D, Hendrick AG, Zahn D, Dixon J, et al. Kisspeptin directly stimulates gonadotropin-releasing hormone release via $\mathrm{G}$ proteincoupled receptor 54. Proc Natl Acad Sci U S A. 2005; 102(5): 1761-6.

49. Thompson E, Patterson M, Murphy K, Smith K, Dhillo W, Todd J, et al. Central and peripheral administration of kisspeptin-10 stimulates the hypothalamic-pituitarygonadal axis. J Neuroendocrinol. 2004; 16(10): 850-8.

50. Dhillo WS, Chaudhri OB, Patterson M, Thompson EL, Murphy KG, Badman MK, et al. Kisspeptin-54 stimulates the hypothalamic-pituitary gonadal axis in human males. J Clin Endocrinol Metab. 2005; 90(12): 6609-15.

51. Dhillo WS, Chaudhri OB, Thompson EL, Murphy KG, Patterson M, Ramachandran R, et al. Kisspeptin-54 stimulates gonadotropin release most potently during the preovulatory phase of the menstrual cycle in women. J Clin Endocrinol Metab. 2007; 92(10): 3958-66.

52. de Roux N, Genin E, Carel J-C, Matsuda F, Chaussain J-L, Milgrom E. Hypogonadotropic hypogonadism due to loss of function of the KiSS1-derived peptide receptor GPR54. Proc Natl Acad Sci U S A. 2003; 100(19): 10972-6.

53. Seminara SB, Messager S, Chatzidaki EE, Thresher RR, Acierno Jr JS, Shagoury JK, et al. The GPR54 gene as a regulator of puberty. N Engl J Med. 2003; 349(17): 1614-27.

54. Chan Y-M, Broder-Fingert S, Paraschos S, Lapatto R, Au M, Hughes V, et al. GnRH-deficient phenotypes in humans and mice with heterozygous variants in KISS1/Kiss1. J Clin Endocrinol Metab. 2011; 96(11): E1771-E81.

55. Topaloglu AK, Tello JA, Kotan LD, Ozbek MN, Yilmaz MB, Erdogan S, et al. Inactivating KISS1 mutation and hypogonadotropic hypogonadism. New England Journal of Medicine. 2012; 366(7): 629-35.

56. Navarro V, Fernandez-Fernandez R, Castellano J, Roa J, Mayen A, Barreiro M, et al. Advanced vaginal opening and precocious activationof the reproductive axis by KiSS-1 peptide, the endogenous ligand of GPR54. J Physiol. 2004; 561(2): 379-86.

57. Tariq A, Shahab M, Clarke I, Pereira A, Smith J, Sultan J, et al. Kiss1 and Kiss1 receptor expression in the rhesus monkey testis: a possible local regulator of testicular function. Central European Journal of Biology. 2013; 8(10): 968-74.

58. Salehi S, Adeshina I, Chen H, Zirkin BR, Hussain MA, Wondisford F, et al. Developmental and endocrine regulation of kisspeptin expression in mouse Leydig cells. Endocrinology. 2015; 156(4): 1514-22.

59. Hsu M-C, Wang J-Y, Lee Y-J, Jong D-S, Tsui K-H, Chiu C-H. Kisspeptin modulates fertilization capacity of mouse spermatozoa. Reproduction. 2014; 147(6): 835-45.

60. Pinto F, Cejudo-Román A, Ravina CG, FernándezSánchez M, Martín-Lozano D, Illanes $M$, et al. Characterization of the kisspeptin system in human spermatozoa. Int J Androl. 2012; 35(1): 63-73.

61. Hua M, Doran J, Kyle V, Yeo S-H, Colledge WH. Does kisspeptin signaling have a role in thetestes? Front Endocrinol (Lausanne). 2013; 4: 198. doi: 10.3389/ fendo.2013.00198.

62. Shahab M, Mastronardi C, Seminara SB, Crowley WF, Ojeda SR, Plant TM. Increased hypothalamic GPR54 signaling: a potential mechanism for initiation of puberty in primates. Proc Natl Acad Sci U S A. 2005; 102(6): 2129-34.

63. Irfan S, Ehmcke J, Wahab F, Shahab M, Schlatt S. Intratesticular action of kisspeptin in rhesus monkey (M acaca mulatta). Andrologia. 2014; 46(6): 610-7.

64. Wahab F, Shahab M. Differential response of the primateHPG axis to N-methyl-D, L-aspartate, but not to Kisspeptin challenge under euglycemic and hypoglycemic conditions. Horm Metab Res. 2012; 44(06): 451-7.

65. Ramaswamy S, Seminara SB, Pohl CR, DiPietro MJ, Crowley Jr WF, Plant TM. Effect of continuous intravenous administration of human metastin 45-54 on the neuroendocrine activity of the hypothalamic-pituitarytesticular axis in the adult male rhesus monkey (Macaca mulatta). Endocrinology. 2007; 148(7): 3364-70.

66. Scott G, Ahmad I, Howard K, MacLean D, Oliva C, Warrington S, et al. Double-blind, randomized, placebocontrolled study of safety, tolerability, pharmacokinetics and pharmacodynamics of TAK-683, an investigational metastin analogue in healthy men. Br J Clin Pharmacol. 
2013; 75(2): 381-91.

67. Wang J-Y, Hsu M-C, Tseng T-H, Wu L-S, Yang K-T, Chiu C-H. Kisspeptin expression in mouse Leydig cells correlates with age. J Chin Med Assoc. 2015; 78(4): 249-57.

68. Ramzan MH, Ramzan M, Ramzan F, Wahab F, Jelani M, Khan MA, et al. Insight into the serum kisspeptin levels in infertile males. Arch Iran Med. 2015; 18(1): $12-7$.

69. Matsui H, Takatsu Y, Kumano S, Matsumoto H, Ohtaki T. Peripheral administration of metastin induces marked gonadotropin release and ovulation in the rat. Biochem Biophys Res Commun. 2004; 320(2): 383-8.

70. Chan Y-M, Butler JP, Pinnell NE, Pralong FP, Crowley Jr WF, Ren C, et al. Kisspeptin resets the hypothalamic GnRH clock in men. J Clin Endocrinol Metab. 2011; 96(6): E908-E15.

71. George JT, Veldhuis JD, Roseweir A, Newton CL, Faccenda E, Millar RP, et al. Kisspeptin-10 is a potent stimulator of LH and increases pulse frequency in men. J Clin Endocrinol Metab. 2011; 96(8): E1228-E36.

72. Young J, George JT, Tello JA, Francou B, Bouligand J, Guiochon-Mantel A, et al. Kisspeptin restores pulsatile LH secretion in patients with neurokinin B signaling deficiencies: physiological, pathophysiological and therapeutic implications. Neuroendocrinology. 2013; 97(2): 193-202.

73. Ramzan F, Qureshi IZ. Intraperitoneal kisspeptin-10 administration induces dose-dependent degenerative changes in maturing rat testes. Life Sci. 2011; 88(5-6): 246-56.

74. Thompson E, Amber V, Stamp G, Patterson M, Curtis A, Cooke J, et al. Kisspeptin-54 at high doses acutely induces testicular degeneration in adult male rats via central mechanisms. Br J Pharmacol. 2009; 156(4): 609-25.

75. Ramzan F, Khan MA, Ramzan MH. The effect of chronic kisspeptin administration on seminal fructose levels in male mice. Endocrine. 2014; 45(1): 144-7.

76. Rajfer J, Swerdloff RS, Heber DM. Testicular histology following chronic gonadotropin-releasing hormone agonist treatment. Fertil Steril. 1984; 42(5): 765-71.

77. Smith JA, Urry RL. Testicular histology after prolonged treatment with a gonadotropin-releasing hormone analogue. J Urol. 1985; 133(4): 612-4.
78. Mayerhofer A, Dubé D. Chronic administrationof a gonadotropin-releasing hormone $(\mathrm{GnRH})$ agonist affects testicular microvasculature. Acta Endocrinol (Copenh). $1989 ; 120(1): 75-80$

79. León MD, Chiauzzi VA, Calvo JC, Charreau $\mathrm{EH}$, Chemes HE. Acute hCG administration induces seminiferous tubuledamage in the adult rat. Acta Physiol Pharmacol Latinoam. 1987; 37(2): 277-88.

80. Kerr J, Sharpe R. Focal disruption ofspermatogenesis in the testis of adult rats after a single administration of human chorionic gonadotrophin. Cell Tissue Res. 1989; 257(1): 163-9.

81. Karaman IM, Kaya C, Ozturk M, Pirincci N, Yimazgumrukcu G, Tuken M. The effects of human chorionic gonadotrophin on normal testicular tissue of rats: dose-dependence and reversibility. BJU Int. 2006; 97(5): 1116-8.

82. Wahab F, Atika B, Shahab M, Behr R. Kisspeptin signalling in the physiology and pathophysiology of the urogenital system. Nat Rev Urol. 2016; 13(1): 21-32.

83. Lasaga M, Debeljuk L. Tachykinins and the hypothalamo-pituitary-gonadal axis: An update. Peptides. 2011; 32(9): 1972-8.

84. Rance NE. Menopause and the human hypothalamus: evidence for the role of kisspeptin/neurokinin B neurons in the regulation of estrogen negative feedback. Peptides. 2009; 30(1): 111-22.

85. Ravina CG, Seda M, Pinto F, Orea A, FernándezSánchez M, Pintado CO, et al. A role for tachykinins in the regulation of human sperm motility. Hum Reprod. 2007; 22(6): 1617-25.

86. Yang JJ, Caligioni CS, Chan Y-M, Seminara SB Uncovering novel reproductive defects in neurokinin B receptor null mice: closing the gap between mice and men. Endocrinology. 2012; 153(3): 1498-508.

87. Ramaswamy S, Seminara SB, Ali B, Ciofi P, Amin NA, Plant TM. Neurokinin B stimulates GnRH release in the male monkey (Macaca mulatta) and is colocalized with kisspeptin in the arcuate nucleus. Endocrinology. 2010; 151(9): 4494-503.

88. Ruiz-Pino F, Garcia-Galiano D, Manfredi-Lozano M, Leon S, Sanchez-Garrido M, Roa J, et al. Effects and interactions of tachykinins and dynorphin on FSH and LH secretion in developing and adult rats. Endocrinology. 2014; 156(2): 576-88.

89. Goodman RL, Coolen LM, Anderson GM, Hardy SL, 


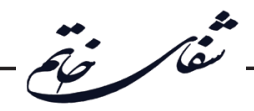

Valent M, Connors JM, et al. Evidence that dynorphin plays a major role in mediating progesterone negative feedback on gonadotropin-releasing hormone neurons in sheep. Endocrinology. 2004; 145(6): 2959-67.

90. Grachev P, Millar RP, O'Byrne KT. The role of neurokinin $\mathrm{B}$ signallingin reproductive neuroendocrinology. Neuroendocrinology. 2014; 99(1): 7-17.

91. Soverchia L, Mosconi G, Ruggeri B, Ballarini P, Catone G, Degl'Innocenti S, et al. Proopiomelanocortin gene expression and $\beta$-endorphin localization in the pituitary, testis, and epididymis of stallion. Mol Reprod Dev. 2006; 73(1): 1-8.

92. Fabbri A, Knox G, Buczko E, Dufau ML. $\beta$-endorphin production by the fetal Leydig cell: Regulation and implications for paracrine control of Sertoli cell function. Endocrinology. 1988; 122(2): 749-55.

93. Fabbri A, Jannini E, Gnessi L, Ulisse S, Moretti C, Isidori A. Neuroendocrine control of male reproductive function. The opioid system as a model of control at multiple sites. J Steroid Biochem. 1989; 32(1): 145-50.

94. Albrizio M, Guaricci AC, Calamita G, Zarrilli A, Minoia P. Expression and immunolocalization of the mu-opioid receptor in human sperm cells. Fertil Steril. 2006; 86(6): 1776-9.

95. Pintar JE, Schachter BS, Herman AB, Durgerian S, Krieger DT. Characterization and localization of proopiomelanocortin messenger RNA in the adult rat testis. Science. 1984; 225(4662): 632-4.

96. Kilpatrick DL, Millette CF. Expression of proenkephalin messenger RNA by mouse spermatogenic cells. Proc Natl Acad Sci U S A. 1986; 83(14): 5015-8.

97. Quill TA, Wang D, Garbers DL. Insights into sperm cell motility signaling through sNHE and the CatSpers. Mol Cell Endocrinol. 2006; 250(1-2): 84-92.

98. Ragni G, De Lauretis L, Bestetti O, Sghedoni D, Gambaro V. Gonadal function in male heroin and methadone addicts. Int J Androl. 1988; 11(2): 93-100.

99. Fujisawa M, Kanzaki M, Okada H, Arakawa S, Kamidono S. Metenkephalin in seminal plasma of infertile men. Int J Urol. 1996; 3(4): 297-300.

100. Sastry BR, Janson VE, Owens LK, Tayeb OS. Enkephalin-and substance P-like immunoreactivities of mammalian sperm and accessory sex glands. Biochem Pharmacol. 1982; 31(21): 3519-22.

101. Foresta C, Tramarin A, Scandellari C, Arslan P.
Effects of a Met-Enkephalin Analogue on motility, O2 Consumption, and ATP Content of Human Spermatozoa. Arch Androl. 1985; 14(2-3): 247-52.

102. Fraioli F, Fabbri A, Gnessi L, Silvestroni L, Moretti C, Redi F, et al. Beta-endorphin, Met-enkephalin, and calcitonin in human semen: evidence for a possible role in human sperm motility. Ann N Y Acad Sci. 1984; 438(1): 365-70.

103. Sharp B, Pekary AE. $\beta$-end0rphin61-91 and other $\beta$-endorphin-immunoreactive peptides in human semen. JCEM. 1981; 52(3): 586-8.

104. Blank MS, Roberts DL. Antagonist of gonadotropinreleasing hormone blocks naloxone-induced elevations in serum luteinizing hormone. Neuroendocrinology. 1982; 35(5): 309-12.

105. Wilkes M, Yen S. Augmentation by naloxone of efflux of LRF from superfused medial basal hypothalamus. Life Sci. 1981; 28(21): 2355-9.

106. Blank MS, Fabbri A, Catt KJ, Dufau ML. Inhibition of luteinizing hormone release by morphine and endogenous opiates in cultured pituitary cells. Endocrinology. 1986; 118(5): 2097-101.

107. Bliesener N, Albrecht S, Schwager A, Weckbecker K, Lichtermann D, Klingmuller D. Plasma testosterone and sexual function in men receiving buprenorphine maintenance for opioid dependence. J Clin Endocrinol Metab. 2005; 90(1): 203-6.

108. Daniell HW. Hypogonadism in men consuming sustained-action oral opioids. J Pain. 2002; 3(5): 37784.

109. Vuong C, Van Uum SH, O’dell LE, Lutfy K, Friedman TC. The effects of opioids and opioid analogs on animal and human endocrine systems. Endocr Rev. 2009; 31(1): 98-132.

110. Cicero TJ, Schainker BA, Meyer ER. Endogenous opioids participate in the regulation of the hypothalamicpituitary-luteinizing hormone axis and testosterone's negative feedback control of luteinizing hormone. Endocrinology. 1979; 104(5): 1286-91.

111. Sirinathsinghji D, Whittington P, Audsley A, Fraser H. $\beta$-Endorphin regulates lordosis in female rats by modulating LH-RH release. Nature. 1983; 301(5895): 62-4.

112. Subirán N, Casis L, Irazusta J. Regulation of male fertility by the opioid system. Mol Med. 2011; 17(7-8): 846-53. 
113. Conklin KA. Dietary antioxidants during cancer chemotherapy: impact on chemotherapeutic effectiveness and development of side effects. Nutr Cancer. 2000; 37(1): 1-18.

114. Conklin KA. Dietary polyunsaturated fatty acids: impact on cancer chemotherapy and radiation. (Review: essential fatty acids/cancer). Altern Med Rev. 2002; 7(1): 4-22.

115. Lamson DW, Brignall M. Antioxidants in cancer therapy; their actions and interactions with oncologic therapies. Altern Med Rev. 1999; 4(5): 304-29.

116. Prasad KN, Kumar A, Kochupillai V, Cole WC. High doses of multiple antioxidant vitamins: essential ingredients in improving the efficacy of standard cancer therapy. J Am Coll Nutr. 1999; 18(1): 13-25.

117. Prasad KN, Cole WC, Kumar B, Prasad KC. Scientific rationale for using high-dose multiple micronutrients as an adjunct to standard and experimental cancer therapies. J Am Coll Nutr. 2001; 20(5): 450S-63S

118. Labriola D, Livingston R. Possible interactions between dietary antioxidants and chemotherapy. Oncology (Williston Park). 1999; 13(7): 1003-8.

119. Agus DB, Vera JC, Golde DW. Stromal cell oxidation: a mechanism by which tumors obtain vitamin C. Cancer Res. 1999; 59(18): 4555-8.

120. Deng S-L, Sun T-C, Yu K, Wang Z-P, Zhang B-L, Zhang $\mathrm{Y}$, et al. Melatonin reduces oxidative damage and upregulates heat shock protein 90 expression in cryopreserved human semen. Free Radic Biol Med. 2017; 113: 347-54.

121. Ahmad R, Haldar C. Effect of intra-testicular melatonin injection on testicular functions, local and general immunity of a tropical rodent Funambulus pennanti. Endocrine. 2010; 37(3): 479-88.

122. Carnevali O, Gioacchini G, Maradonna F, Olivotto I, Migliarini B. Melatonin induces follicle maturation in Danio rerio. PLoS One. 2011; 6(5): e19978.

123. Sanchez-Barcelo EJ, Mediavilla MD, Vriend J, Reiter RJ. Constitutive photomorphogenesis protein 1 (COP 1) and COP 9 signalosome, evolutionarily conserved photomorphogenic proteins as possible targets of melatonin. J Pineal Res. 2016; 61(1): 41-51.

124. Cipolla-Neto J, Amaral F, Afeche S, Tan D, Reiter R. Melatonin, energy metabolism, and obesity: a review. J Pineal Res. 2014; 56(4): 371-81.
125. Odawara H, Iwasaki T, Horiguchi J, Rokutanda N, Hirooka K, Miyazaki W, et al. Activation of aromatase expression by retinoic acid receptor-related orphan receptor (ROR) alpha in breast cancer cells: identification of a novel ROR response element. J Biol Chem. 2009; 284(26): 17711-9.

126. Qin F, Zhang J, Zan L, Guo W, Wang J, Chen L, et al. Inhibitory effect of melatonin on testosterone synthesis is mediated via GATA-4/SF-1 transcription factors. Reprod Biomed Online. 2015; 31(5): 638-46.

127. Casao A, Pérez-Pé R, Abecia JA, Forcada F, MuiñoBlanco T, Cebrián-Pérez JÁ. The effect of exogenous melatonin during the non-reproductive season on the seminal plasma hormonal profile and the antioxidant defence system of Rasa Aragonesa rams. Anim Reprod Sci. 2013; 138(3-4): 168-74.

128. Mura MC, Luridiana S, Bodano S, Daga C, Cosso $\mathrm{G}$, Diaz ML, et al. Influence of melatonin receptor 1A gene polymorphisms on seasonal reproduction in Sarda ewes with different body condition scores and ages. Anim Reprod Sci 2014; 149(3-4): 173-7.

129. Ansel L, Bentsen AH, Ancel C, Bolborea M, Klosen P, Mikkelsen JD, et al. Peripheral kisspeptin reverses short photoperiod-induced gonadal regression in Syrian hamsters by promoting GNRH release. Reproduction. 2011; 142(3): 417-25.

130. Henningsen JB, Poirel VJ, Mikkelsen JD, Tsutsui K, Simonneaux V, Gauer F. Sex differences in the photoperiodic regulation of RF-Amide related peptide (RFRP) and its receptor GPR147 in the syrian hamster. J Comp Neurol. 2016; 524(9): 1825-38.

131. Xu J, Li P. Expression of EAP1 and CUX1 in the hypothalamus of female rats and relationship with KISS1 and GnRH. Endocr J. 2016; 63(8): 681-90.

132. Li C, Zhou X. Melatonin and male reproduction. Clin Chim Acta. 2015; 446: 175-80.

133. Baburski AZ, Sokanovic SJ, Janjic MM, StojkovMimic NJ, Bjelic MM, Andric SA, et al. Melatonin replacement restores the circadian behavior in adult rat Leydig cells after pinealectomy. Mol Cell Endocrinol. 2015; 413: 26-35.

134. Bilińska B, Schmalz-Frączek B, Kotula M, Carreau S. Photoperiod-dependent capability of androgen aromatization and the role of estrogens in the bank vole testis visualized by means of immunohistochemistry. Mol Cell Endocrinol. 2001; 178(1-2): 189-98.

135. Carreau S. Germ cells: a new source of estrogens 


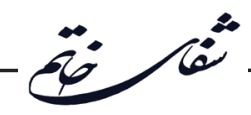

in the male gonad. Mol Cell Endocrinol. 2001; 178(12):65-72.

136. Deng S-L, Wang Z-P, Jin C, Kang X-L, Batool A, Zhang $\mathrm{Y}$, et al. Melatonin promotes sheep Leydig cell testosteronesecretion in a co-culture with Sertoli cells. Theriogenology. 2018; 106: 170-77.

137. Gholami M, Saki G, Hemadi M, Khodadadi A, Mohammadi-asl J. Melatonin improves spermatogonial stem cells transplantation efficiency in azoospermic mice. Iran J Basic Med Sci. 2014; 17(2): 93-9.

138. Ferin M, Van Vugt D, Wardlaw S, editors. The hypothalamic control of the menstrual cycle and the role of endogenous opioid peptides. Recent Prog Horm Res. 1984; 40: 441-85.

139. Foradori CD, Coolen LM, Fitzgerald ME, Skinner DC, Goodman RL, Lehman MN. Colocalization of progesterone receptors in parvicellular dynorphin neurons of the ovine preoptic area and hypothalamus. Endocrinology. 2002; 143(11): 4366-74.

140. Rometo A, Rance NE. Changes in prodynorphin gene expression and neuronal morphology in the hypothalamus of postmenopausal women. J Neuroendocrinol. 2008; 20(12): 1376-81.

141. Moenter SM, Brand RC, Karsch FJ. Dynamics of gonadotropin-releasing hormone $(\mathrm{GnRH})$ secretion during the GnRH surge: insights into the mechanism of
GnRH surge induction. Endocrinology. 1992; 130(5): 2978-84.

142. Topaloglu AK, Reimann F, Guclu M, Yalin AS, Kotan LD, Porter KM, et al. TAC3 and TACR3 mutations in familial hypogonadotropic hypogonadism reveal a key role for Neurokinin B in the central control of reproduction. Nat Genet. 2009; 41(3): 354-8.

143. Guran T, Tolhurst G, Bereket A, Rocha N, Porter K, Turan S, et al. Hypogonadotropic hypogonadism due to a novel missense mutation in thefirst extracellular loop of the neurokinin B receptor. J Clin Endocrinol Metab. 2009; 94(10): 3633-9.

144. Pastor CL, Griffin-Korf ML, Aloi JA, Evans WS, Marshall JC. Polycystic ovary syndrome: evidence for reduced sensitivity ofthe gonadotropin-releasing hormone pulse generator to inhibition by estradiol and progesterone. J Clin Endocrinol Metab. 1998; 83(2): $582-90$.

145. Roseweir AK, Kauffman AS, Smith JT, Guerriero KA, Morgan K, Pielecka-Fortuna J, et al. Discovery of potent kisspeptin antagonists delineate physiological mechanisms of gonadotropin regulation. J Neurosci. 2009; 29(12): 3920-9.

146. Blank S, McCartney C, Marshall J. The origins and sequelae of abnormal neuroendocrine functionin polycystic ovary syndrome. Hum Reprod Update. 2006; 12(4): 351-61. 